\title{
THE STATE OF THE ART OF NURSE ROSTERING
}

\author{
EDMUND K. BURKE ${ }^{1}$, PATRICK DE CAUSMAECKER ${ }^{2}$, GREET VANDEN BERGHE², \\ AND HENDRIK VAN LANDEGHEM ${ }^{3}$ \\ ${ }^{1}$ School of Computer Science \& IT, University of Nottingham, Jubilee Campus, Nottingham NG8 1BB, UK \\ ${ }^{2}$ KaHo St.-Lieven, Information Technology, Gebr. Desmetstraat 1, 9000 Gent, Belgium \\ ${ }^{3}$ Vakgroep Technische Bedrijfsvoering, Universiteit Gent, Technologiepark 903, 9052 Gent-Zwijnaarde, Belgium
}

\begin{abstract}
Nurse rostering is a complex scheduling problem that affects hospital personnel on a daily basis all over the world. The need for quality software solutions is acute for a number of reasons. In particular, it is very important to efficiently utilise time and effort, to evenly balance the workload among people and to attempt to satisfy personnel preferences. A high quality roster can lead to a more contented and thus more effective workforce.

In this review, we discuss nurse rostering within the global personnel scheduling problem in healthcare. We begin by briefly discussing the review and overview papers that have appeared in the literature and by noting the role that nurse rostering plays within the wider context of longer term hospital personnel planning. The main body of the paper describes and critically evaluates solution approaches which span the interdisciplinary spectrum from operations research techniques to artificial intelligence methods. We conclude by drawing on the strengths and weaknesses of the literature to outline the key issues that need addressing in future nurse rostering research.
\end{abstract}

KEY WORDS: nurse rostering, hospital personnel scheduling

\section{INTRODUCTION}

Employee scheduling has been addressed by personnel managers, operations researchers and computer scientists for more than 40 years. The domain often covers staffing, budgeting and short-term scheduling problems. Although these fields each have different time horizons, they are strongly interrelated. The scheduling of hospital personnel is particularly challenging because of different staffing needs on different days and shifts. Unlike many other organisations, healthcare institutions work around the clock. Irregular shift work has an effect on the nurses' well being and job satisfaction (Mueller and McCloskey, 1990; Oldenkamp, 1992). The extent to which the staff roster satisfies the staff can impact upon the working environment (Akerstedt, 1985; Kostreva and Genevier, 1989; Monk, 1986; Monk and Folkard, 1992; Wilkinson and Allison, 1989).

Until recently, most personnel scheduling problems in hospitals were solved manually. This is sometimes called 'self-scheduling' in the literature (e.g. Miller, 1984; Ringl and Dotson, 1989; Silvestro and Silvestro, 2000). Scheduling by hand used to be a very time consuming task. Planners had no automatic tool to test the quality of a constructed schedule. They made use of very straightforward constraints on working time and idle time in the recurring process. In fact,

Edmund Burke: E-mail: ekb@cs.nott.ac.uk. Patrick De Causmaecker: E-mail: patrick.decausmaecker@kahosl.be. Greet Vanden Berghe: E-mail: greet.vandenberghe@kahosl.be. Hendrik Van Landeghem: E-mail: hendrik.vanlandeghem@ ugent.be. 
many of the hospitals with computerised scheduling systems are not exploiting the full range of capability that is possible. Scheduling editing features are often used but automatic schedule generation features are still not common. The importance of a systematic approach to create good timetables is very high, especially in healthcare, where it is unacceptable not to fully support patient care needs and staff requirements. Automated approaches hold significant potential for improving the timetabling process and the quality of those timetables. Mathematical or heuristic approaches can easily produce a number of solutions, they can report upon the quality of schedules and they can try to divide the work evenly among personnel. One of the most significant benefits of automating the personnel scheduling process is a very considerable time-saving for the administrative staff involved.

Although the main overall goal of hospital personnel scheduling and other employee scheduling problems is the same, the problems often differ considerably and so do the approaches to solve them. In this article, we present an overview of nurse rostering both from the problem formulation (Section 2) and from the solution method perspective (Section 3). In this paper, we concentrate on Nurse Rostering. However, we have to point out that the term 'rostering' has several different meanings across the literature. Wren (1996) defined rostering as "the placing, subject to constraints, of resources into slots in a pattern. One may seek to minimise some objective, or simply to obtain a feasible allocation. Often the resources will rotate through a roster". In the literature, 'nurse rostering' often refers to the short term timetabling of staff (with a typical time horizon of a few weeks). In this article, we will use the term nurse rostering to refer to this process (the allocation of nurses to periods of work over several weeks).

In general hospital personnel scheduling, different approaches exist for various time horizons. Since this article concentrates on the short-term timetabling part of the problem, we will only briefly discuss longer term management decision making (which we refer to as staffing). Section 2.2 especially stresses the differences between nurse rostering and longer term planning.

In this paper we will employ the following terminology:

- Planning Period. The planning period is the time interval over which the staff have to be scheduled. A typical length of the planning period is 4 weeks.

- Skill Category. This determines a class of staff who have a particular level of qualification, skill or responsibility.

- Shift Type. Shift types are hospital duties which usually have a well-defined start and end time. Many nurse rostering problems are concerned with the three traditional shifts (or slight variants thereof) early (e.g. 7:00-15:00), late (15:00-22:00), and night (22:00-7:00).

- Coverage Constraints. Coverage constraints express the number of personnel needed for every skill category and for every shift or time interval during the entire planning period. They are often referred to as personnel demands or personnel requirements. It is very common in hospitals that the coverage constraints have been determined by a sort of workload measurement system (e.g. patient classification system), nurse-patient ratios or by a forecasting method.

- Time Related Constraints. These constraints refer to all the restrictions on personal schedules. All the personal requests, personal preferences, and constraints on balancing the workload among personnel belong to this category.

- Hard Constraints are those that must be satisfied at all costs.

- Soft Constraints are those that are desirable but which may need to be violated in order to generate a workable solution.

- Work Regulations. The contract that personnel members have with the hospital is called a 'work regulation'. It sets a number of time related constraints for the nurses. 
As an illustrative example of a nurse rostering problem to highlight how this terminology is used, we consider a hospital ward with the following members of staff (and their particular skill category): 1 head nurse, 15 regular nurses, 3 caretakers and 2 trainees. Shift types include early, day, late and night shifts. Among the personnel, some people's work regulations are full time (which means that the person should work for example 38 hours a week, with a maximum of 6 assignments to the night shift type and a maximum of 2 weekends per month). Other work regulations are half time (where there is a maximum of 10 assignments per month and at most 20 hours per week). Some nurses even work to a personal work regulation (for example restricting the number of Wednesday afternoon shifts). Apart from the time related constraints that are defined by the work regulations, every single nurse can specify preferences (such as a request for a particular day off). The work regulation of the trainees indicates, for example, that a trainee should only be assigned to a shift type when the supervisor is assigned to that same shift type. Coverage constraints are generally imposed upon the ward by the management. Every 4 weeks the head nurse needs to create a roster. In order to generate a feasible solution, the coverage constraints for every skill category and for every single day (and shift type) of the 4 week planning period need to be met (we refer to the coverage constraints as hard constraints in this example). While doing that, the head nurse will attempt to minimise the number of violations of time related constraints (which we are taking to be soft constraints in this example). There is an extremely high number of possible solutions to this rather simple example of a nurse rostering problem.

The motivation for this article is twofold. Firstly, we aim to provide a comprehensive overview of the current scientific state-of-the-art in automated nurse rostering and to critically review the extensive collection of scientific literature that has been generated over the last forty years. We aim to highlight the key scientific achievements in that time. Secondly, by analysing the current state of the art, we will outline what we believe to be the important research issues that have not been fully addressed by the scientific community. We will present some of the problems and issues that should be addressed in the next few years.

\section{NURSE SCHEDULING-DESCRIPTION OF MODELS}

The terms nurse rostering or nurse scheduling have been used over the years to cover several types of personnel scheduling problem. In the literature (e.g. Bradley and Martin, 1990; Siferd and Benton, 1992; Tien and Kamiyama, 1982; Warner, 1976), the terms 'staffing' and 'rostering' are used to handle different decision levels. The adoption of manual or automated scheduling methods or whether to employ cyclical or non-cyclical scheduling are important decisions which lead to completely different solutions. In this section, we will concentrate on such strategic decisions. We will begin by briefly discussing previous survey articles. Most of them specifically tackle personnel scheduling in healthcare.

\subsection{Literature overviews}

In an influential early overview, Warner (1976), distinguishes 3 major areas of manpower decision research: staffing, scheduling and reallocation of nurses. Five different criteria are defined for the scheduling part of the problem:

- coverage: how different the required and the scheduled number of people for a task are.

- quality: how fair schedules are, what the work stretch length is. 
- stability: how the nurses perceive the schedules (in terms of consistency, predictable on/off days and weekend work).

- flexibility: how well the system can adapt to changes in the environment.

- cost: how many resources are consumed in making the decision: e.g. personnel manager's time or computer time.

It is very interesting to combine these criteria for evaluating schedules since they address more than computable standards. From a general hospital scheduling point of view, it makes sense to take such a broad interpretation of cost (to generate the schedule) into account. However, it would also make sense to add other criteria (like 'personnel cost', for example) to the list. Nearly all the criteria are very hard to measure. Warner compares three scheduling approaches against these 5 criteria:

- In the Traditional Approach, the schedules are generated by hand. This policy is flexible, which is the only advantage with respect to the criteria.

- Cyclical Scheduling generally provides good schedules but it cannot easily address personal requests.

- Computer Aided Traditional Scheduling enables a fast and more complete search for good schedules. The advantages of this approach are high with respect to all the criteria considered.

Warner's overview is oriented towards techniques for determining desired/required staffing levels, which are also briefly discussed in Section 2.2.

Fries (1976), presents a bibliography of early methods for personnel rostering in healthcare institutions. Many of these early approaches rely on manual procedures, following a set of arbitrary rules. They are too restricted to be directly applicable for large modern hospitals with today's complexity. However, there is always the possibility of hybridising early approaches (or some features of early approaches) with more sophisticated modern techniques to produce even better methods.

Tien and Kamiyama (1982), present a list of personnel scheduling algorithms, which are not restricted to healthcare. Many of them are based on trial and error methods. Tien and Kamiyama concentrate on the hospital scheduling situation in the United States. A particularly interesting contribution is that they decompose the 'manpower' scheduling problem into five separate stages: determination of temporal manpower requirements, total manpower requirement, recreation blocks, recreation/work schedule, and shift schedule. Stages 1 and 2 are management decisions (also called the 'manpower allocation problem'), which belong to the long-term staffing part of the problem. Both stages consider the definition of hospital requirements and the selection of resources. Stages 3 to 5 include the entire short-term timetabling part of the problem, that takes preferences and constraints on personal schedules into account. Tien and Kamiyama were able to classify many papers in their 5 stage model, some covering a number of stages simultaneously. However, we believe that this division is often too simplified to capture all the problem specific features of modern nurse rostering problems.

Sitompul and Randhawa (1990), concentrate on financial cost. The goal is to reduce the personnel cost. Characteristics of manpower scheduling in hospitals are fluctuating demand, human effort (which cannot be inventoried), and critical customer convenience, while the schedules are subject to different kinds of constraints. They define four stages in nurse scheduling:

- Determine a set of feasible schedules that satisfy the constraints.

- Select the best schedule in terms of cost, coverage, and/or other criteria. 
- Fine tune to accommodate changes.

- Make specific shift assignments.

It is interesting to compare schedules with respect to the perceived quality by the personnel members instead of using the violation of constraints as a criterion. In practice, it often makes no sense to separate specific shift assignments from the schedule design because assignment to different people really influences the quality of the schedule. Sitompul and Randhawa advocate the approach of tackling staffing and rostering at the same time. They argue that separating the rostering from management decisions leads to sub-optimal schedules. From a theoretical point of view, this is absolutely true. However, we believe that a general scheduling procedure would not work without significant changes in working practices, for the following reasons:

- Even though there is a high fluctuation in patient needs, it is not recommended to shift personnel around the hospital each time the request does not match the available staff. This would be the consequence if the problem were looked at from a purely global point of view.

- People prefer to express personal preferences with respect to work and free time. These preferences differ from month to month. Planners only seem to grant personnel wishes if they know the people in person.

- The problems are nearly all over-constrained and far too complex to find an optimal solution in a reasonable amount of time. Splitting them up cannot lead to optimality either but it certainly results in less complex subproblems.

Warner, Keller, and Martel (1990), discuss patient-oriented and employee-oriented issues in nurse management. The latter are divided into several 'chronological' areas. The most interesting one is called short range scheduling and staffing. It includes the weekly, daily, or shift by shift adjustments to the long range schedule. The paper contains a description of the history of computerised nurse scheduling in the US. The article also introduces a nurse scheduling system called ANSOS (Automated Nurse Scheduling Office System) which will be discussed in more detail in Section 3. Warner et al. demonstrate a deep appreciation for the difficulties involved in tackling real world nurse rostering problems.

Bradley and Martin (1990), distinguish three basic decisions in hospital personnel scheduling: staffing, personnel scheduling and allocation (as introduced by Warner, 1976). The first problem consists of determining the long-term number of personnel that have to be employed. The number of personnel is expressed in terms of full time equivalents and is supposed to be sufficient to cover holiday periods (annual leave), training and further education. Hiring part-time nurses and allowing flexible work (or permitting the definition of different work agreements) facilitates a closer match between the personnel demands and the effective hours worked. Staffing decisions are influenced by the stochastic nature of personnel requirements and personnel capabilities. The second phase in Bradley and Martin's decision scheme is the conversion of the expected daily work force into precise assignments i.e. personnel rostering. Better schedules can be generated if the problem allows for differentiation between days of the week and seasonal variations. Since schedules are generated before the actual patient needs are known, the personnel manager or scheduler has to anticipate the personnel requirements. The third phase (allocation) consists of assigning the scheduled personnel to actual work sites. It enables the hospital to correct schedules as fluctuations in the demands occur. The time horizon for the allocation phase is typically very short (varying from a few hours to a couple of days). 
Bradley and Martin present a useful classification of schedules both formally and from a solution method viewpoint, just like Sitompul and Randhawa (1990) do. These can be summarised as: exact cyclical, heuristic cyclical, exact non-cyclical, and heuristic non-cyclical.

Siferd and Benton (1992), present an excellent review of the factors influencing hospital staffing and scheduling in the United States. A survey among hospital managers reveals the complexity of the problem. The work first discusses the staffing history in which cost reduction became more and more important. In the second part of the work, short-term personnel scheduling is discussed, in which various constraints on the nurses' schedules are taken into account. The researchers collected data from 31 different hospitals and, in total, 348 wards. Decentralised manual scheduling was the most common approach, often performed in co-operation with a large number of people per ward. The questioned hospitals worked with different skill categories for personnel. Personnel shortage is often solved by allowing overtime (sometimes leading to working days of 12 or 16 hours) and by using personnel from other wards. Full time work seemed to be more popular than any kind of part time work. It was also rather rare to have nurses doing both day and night shifts. In some cases the night work was carried out by a special group of personnel (but this does not generally hold). A large number of personnel is assigned to a set shift in practice. Most shifts have fixed start and end times. $50 \%$ of the hospitals work with three start times for day shifts on weekdays and $30 \%$ have 5 different start times. Most hospitals seem to work with stricter rules (e.g. in $93 \%$ of the cases, either there are no 'split' shifts, or, people are working the same days every week). This is an excellent paper which fully illustrates the difficulty of nurse rostering problems in practice.

Hung (1995), collected 128 articles on nurse scheduling, from the 60's up until 1994, and he presents a brief overview. Most papers study the experience of new work week arrangements. The overview is just a bibliographic selection but it can be useful for collecting literature from a variety of research domains.

Cheang et al. (2003), present a survey of recent models and approaches for the nurse rostering problem. The paper does not attempt to critically evaluate the area but, as the authors say, its purpose is to provide a "brief overview" of the area. The emphasis of the paper is on briefly covering mathematical programming methods, different kinds of constraint programming techniques and metaheuristics.

Ernst et al. (2004), present a very comprehensive overview of the literature on staff scheduling and rostering. They concentrate on staff scheduling that they describe in general rather than concentrating on nurse rostering in particular. They have split the paper into three main parts:

- definitions, classification of personnel scheduling problems

- a classification of the literature into application areas

- solution methods, with comments on applicability.

Ernst et al. describe the personnel scheduling and rostering problem in detail. An extensive list of terminology and problem characteristics is introduced. They deliberately do not distinguish between rostering and scheduling. However, in a very interesting section about common decompositions of the problem, one of the described proposals is to present demand modelling as a separate module. Many of the characteristics that they describe apply to staff scheduling problems other than nurse rostering.

When discussing their classification by application area, most attention is paid to crew scheduling and rostering. They consider this to be the best covered application domain. However, one of their categories specifically discusses health care systems and it is mainly concerned with nurse scheduling and rostering. Ernst et al. discuss, more or less in historical order, nurse rostering 
approaches as they have been reported upon in the literature. They point out that mathematical programming and metaheuristic approaches are by far the most investigated techniques, in the literature on personnel scheduling. They point out that metaheuristics are promising for very difficult problems and for real world problems for which optimal solutions cannot be obtained with exact approaches.

Ernst et al. highlight a few areas for improvement in the personnel scheduling and rostering domain:

- widening the applicability by generalising models and methods,

- gaining more efficiency through a better integration of the problem steps,

- increasing the accessibility by integrating the tools in Enterprise Resource Planning systems,

- catering for individual preferences,

- generalising the rostering algorithms.

We cover some of these issues in Section 4.

There are a few $\mathrm{PhD}$ dissertations on the topic of hospital scheduling. Most of them belong to the staffing domain. They are briefly summarised in Appendix A.

It is clear that nurse scheduling problems have been addressed across a wide spectrum of research articles. It is also clear that some papers in the literature have tackled simplified problems and have developed methods which cannot be directly applied to hospitals. Even in the early days of automated nurse rostering (Warner, 1976), there was an awareness of requirements other than just measurable optimisation objectives. Automated schedule generation needs to be flexible, to consider personal preferences, patient satisfaction, and human effort (Sitompul and Randhawa, 1990; Tien and Kamiyama, 1982). In particular, Siferd and Benton started to show the way by highlighting the complexity of the real world problem. Too many scientific articles in the past have not addressed this complexity. As we shall see, this is a theme which will recur in this paper and, indeed, it is one of our main conclusions.

The early papers on nurse scheduling research often considered the entire process of staffing, assigning people to wards, and short-term timetabling as a whole. The most recent overviews started to decompose the problem.

In Section 2.2, we will briefly discuss long term management decisions (which we call staffing) which are made before the rostering process starts.

\subsection{Staffing}

Hospital staffing involves determining the number of personnel of the required skills in order to meet predicted requirements. It is also called workforce scheduling in other personnel planning environments such as production scheduling and cargo forwarding. In practice, several interrelated considerations make the task very complex (Gillies, 1989). Factors include organisational structure and characteristics, personnel recruitment, skill categories of the personnel, working preferences (Gray, McIntire, and Doller, 1993), patient needs and circumstances in particular nursing units. Another significant staffing decision is to define work agreements for part time workers and to decide whether substitution of skill categories is allowed (and for which people). In real world problems staffing, budgeting and personnel rostering often take place at different levels and for completely different time horizons. Many researchers have therefore decomposed the nurse rostering problem into phases (3 phases in Bradley and Martin, 1990; Warner, 1976, in Sitompul 
and Randhawa (1990), and 5 in Tien and Kamiyama (1982)). Interaction between the levels is certainly necessary but in practice it would be unworkable to handle them simultaneously all the time. Personnel are usually hired for longer periods than the short-term rostering period. Although staffing and hospital management decisions are beyond the scope of this paper, a brief summary of some key articles is presented mainly because of the impact that different kinds of input data can have on the short-term nurse rostering problem.

Note that the literature overviews from Section 2.1 (Bradley and Martin, 1990; Siferd and Benton, 1992; Sitompul and Randhawa, 1990; Tien and Kamiyama, 1982; Warner, 1976), nearly all concern staffing issues in addition to rostering.

As early as 1963, Wolfe and Young (1965a, b), presented a model to minimise the cost for assigning nurses of different skill categories to various tasks.

In addition to dealing with rostering (discussed above), Warner (1976), also deals with staffing in some detail. He defines the staffing problem as an annual decision in which seasonal variation can be considered. It consists of determining an appropriate number of full time equivalent nurses for each skill category. A methodology for the staffing decision is proposed by Warner and many hospitals accept it (subject to small adaptations). After the scheduling phase comes the third step: the reallocation of nurses. This phase is a fine-tuning of staffing and scheduling. It involves determining how float nurses are assigned to units based on nonforecastable changes or absenteeism. Among hospital schedulers, the potential benefits of this reallocation step in the process are uncertain. However, Warner is convinced that the combination of the three stages in the end leads to a better scheduling policy. Warner's paper represents a key contribution to nurse staffing.

de Vries (1987), developed a 'management control framework' to balance the supply and the demand for nursing care. There seems to be an acceptable range of balance between supply and demand instead of a strict equilibrium. de Vries calculates the actual capacity utilisation by dividing the workload per hour by the available staff per hour. Theoretically, uniform criteria could hold for all wards in the hospital. However, differences in workload between wards can be registered and result in a mechanism for co-ordination between wards.

The performance of the framework has been tested for real examples and the stability could be improved in a few cases. We believe that this is mainly due to the flexibility of setting parameters separately per ward, and to the expert knowledge on the floor that is used for forecasting the workload.

Smith-Daniels, Schweikhart, and Smith-Daniels (1988), present a literature overview on capacity planning in healthcare. They distinguish between capacity decisions on facility resources and on work-force resources. In these categories, two decision levels are selected: acquisition decisions and allocation decisions.

The acquisition decisions for work-force resources match the meaning of 'staffing' as it is defined in this section. Two other decisions in the group are the assignment of workers to units and to tasks. A useful contribution of the paper is the collection of many different strategies and approaches for the decision maker. Smith-Daniels et al. predict that the strict staffing and timetabling of people and other resources will all be combined in an objective for new large scale health organisations.

The allocation decisions for work-force resources, namely the assignment of workers to days and shifts, is not deeply studied in the paper. It may therefore be problematic to believe that the integration of all the planning categories into one objective will be applicable to complex real world problems.

Easton, Rossin, and Borders (1992), compare different staffing policies during a one month period in a large hospital in the United States. They are attempting to provide adequate staffing 
levels to meet the patient's needs and attractive work schedules to satisfy the personnel. The research is carried out at the management level, considering costs and the annual percentage of personnel turnover, reflecting dissatisfaction. It is a common problem in hospital environments that unplanned capacity adjustments have to be made from time to time. In busy periods, unscheduled nurses will be expected to work, and in slack periods, people will work too few hours to earn their full wages. Restrictions on shift rotation and work stretches, distribution of unattractive work, higher wages for weekend and night work and 12-hour shifts during the weekend are considered. In 1992, alternative scheduling patterns (called ALTOURs in Easton, Rossin, and Borders, 1992) were becoming common in nurse scheduling environments. The patterns involve $8,10,12$ or 16 hour shifts, combined with days off patterns and compensation days. Easton et al. also discuss the possibility of working with 'float' nurses. Float nurses can easily solve temporarily occurring under- and overstaffing in different wards. It is not recommendable however, to ask float nurses to undertake high risk tasks that require a lot of experience, such as working in intensive care and assisting in an operating theatre.

Finally, the paper presents the results of 12 different methods. It compares scheduled hour utilisation, paid hours, workforce distribution, and the number of different 'tours' (see also Section 2.4) for both unit scheduling and centralised scheduling (see Section 2.3). They conclude that the expected nursing expenses decrease as the scheduling alternatives increase. In order to obtain this result, the nursing requirements have to obey a number of rules that are explained in the paper. The research also excludes overtime, part-time work, and understaffing because it is very hard to formalise them. The results of Easton, Rossin, and Borders (1992) are thus quite problem specific. Due to different staffing and rostering policies in different hospitals, we believe that some of these extra parameters need to be taken into account in order to make the methods more widely applicable.

A few publications exist on simulation for personnel staffing in the emergency room (Draeger, 1992; Kumar and Kapur, 1989). Although staffing policies are beyond the scope of pure nurse rostering, the rostering algorithms have to handle the results of management decisions at a high level. In some hospitals staffing and scheduling information is used to support structural change.

\subsection{Administrative modes of operation}

Different hospitals around the world have very different administrative procedures that lead to very different types of nurse rostering problems. We will briefly cover some of the main modes of operation in this section.

Centralised scheduling is a term that is sometimes used to describe the situation where one administrative department in a hospital carries out all the personnel scheduling (Easton, Rossin, and Borders, 1992; Siferd and Benton, 1992; Smith-Daniels, Schweikhart, and Smith-Daniels, 1988; Warner, 1976). It relieves head nurses from the time consuming task of constructing schedules on a very regular basis. The major advantage of this approach is the opportunity for cost containment through better use of resources. However, centralised scheduling suffers from a number of limitations: personnel can feel that local ward requirements are not fed into the procedure, that the rosters are unfair, or even that there is favouritism (see Silvestro and Silvestro, 2000 for more details).

When head nurses or unit managers are given the responsibility to generate the schedules locally, the process is sometimes called unit scheduling (Aickelin and Dowsland, 2000; Bradley and Martin, 1990; Dowsland, 1998; Meisels, Gudes, and Solotorevski, 1996; Meyer auf'm Hofe, 1997; Sitompul and Randhawa, 1990). 
Self-scheduling is a term sometimes used to describe the situation when the personnel roster is generated manually by the staff themselves (often with little or no computer aided support). The term 'interactive scheduling' is also sometimes used in this respect (e.g. Miller, 1984; Ringl and Dotson, 1989). Manually creating schedules has been generally adopted in hospital wards. Self-scheduling is more time consuming than automatic scheduling but it has the advantage that the nurses co-operate and are asked for advice. Generally it is performed by the personnel members themselves and co-ordinated by the head nurse of a ward. Nurses and other personnel collectively develop their schedules, taking coverage and time-related constraints into account. While the individual personnel members express their preferences for schedules and help setting the number of people required at any time, the personnel manager ensures that the hospital requirements are met. It is a very labour intensive procedure in which the nurses indicate their preferences and negotiate during breaks and before and after a shift. Some studies show that self-scheduling has significant drawbacks. In Silvestro and Silvestro (2000), for example, it is said that the process can easily lead to over- or understaffing, that the schedule is made for the convenience of staff, and that there are no formal procedures for conflict solving.

Miller (1984), states that self-scheduling increases perceptions of autonomy among staff nurses, it reduces the head nurse's scheduling time, and it eliminates most of the special requests. The research is based on the implementation of self-scheduling in one single ward in a US hospital without comparing it with other nurse rostering environments. Hung (1992), looked at more US hospitals and he identified a number of motivational benefits of self-scheduling. He states that it leads to greater staff satisfaction and commitment, it improves co-operation and team work and it reduces the staff turnover. Both authors found that self-scheduling yields more effective rosters because the personnel know that their personal preferences are taken into account and consequently they are more willing to co-operate.

Silvestro and Silvestro (2000), discuss the results of a survey of nurse rostering practices in the UK National Health Service. They define the three different scheduling policies discussed in this section as follows:

- Departmental rostering which is conducted by the charge nurse or delegated to a staff nurse.

- Team rostering, where staff are divided into teams and a nominated member of each team has the responsibility for rostering, in consultation with team members.

- Self-rostering, where the roster is prepared by the ward staff.

In the practical nurse rostering problems that Silvestro and Silvestro studied, they identify 4 key determinants of rostering problem complexity:

- Ward size (measured by the number of staff).

- Predictability of demand (measured by the ratio of planned and emergency operations). This measure has not been studied in detail in our article because it is not part of the short term rostering problem.

- Demand variability (based on the variability in the length of patient stay and the degree of variation in the manning requirement over a working week).

- Complexity of skill mix (measured in terms of the degree of variation in staff grades and the complexity of the manning requirement specification).

For comparing the difficulty of a wider variety of problems (Appendix B), we had to consider more measures than these four. Most of them are related to a more flexible shift type definition than the Early-Late-Night shifts discussed in Silvestro and Silvestro (2000). 
Although certain papers in the literature advocate self-scheduling (Miller, 1984; Ringl and Dotson, 1989), Silvestro and Silvestro conclude that the benefits and limitations depend on the operational context (ward size and rostering complexity). Departmental rostering seems more appropriate and effective for large wards with difficult rostering problems. Team rostering appears to be more suitable for medium sized wards with relatively easy problems, while self-rostering works well in small wards with relatively straightforward problems. Although self-rostering is more favourable (according to the management literature (Miller, 1984; Ringl and Dotson, 1989)), due to its empowerment and motivational benefits, there is a danger of generating unbalanced and inappropriate rosters.

\subsection{Cyclical scheduling}

In this section we will briefly discuss cyclical scheduling which concerns organisations in which each person works a cycle of $n$ weeks (Howell, 1966). This approach has some serious drawbacks for practical applications but it has received some discussion in the literature over the years. This type of schedule is common if the day is partitioned in distinct shifts and if the personnel requirements per day and per shift obey a cyclical pattern. Cyclical scheduling is also referred to as 'fixed' scheduling, while non-cyclical scheduling is sometimes called 'flexible' (Silvestro and Silvestro, 2000).

According to Warner (1976), cyclical schedules offer several advantages. Personnel know their schedule a long time in advance, the same blocks are used repeatedly, the work is divided evenly, and unhealthy work rotations are avoided because it is common to apply 'forward' rotation. Forward rotation is met when a schedule includes no shift starting at an earlier time than a shift on the day before.

Megeath (1978) proposed cyclical 7-day patterns of shifts and days off to allow for balanced shift coverage. There are clear benefits but cyclical schedules do not have high levels of flexibility. They cannot easily address flexible work regulations, fluctuating personnel demands and personal preferences. Also, cyclical scheduling requires a higher level decision to provide a precise number of skilled personnel members and strict personnel tasks. Working according to cyclical schedules is impossible if the problem is not stated in a very precise and correct manner.

Burns and Koop (1987), developed a cyclical model for manpower scheduling with strict specifications on consecutive working days and days off. It takes only three different shift types into consideration. The model is not flexible enough to deal with complex modern nurse rostering problems.

Hung (1991), presents a cyclical pattern for short-term nurse scheduling. He introduces 4-day workweeks with 10-hour shifts. Hung states that long shifts have benefits if the overlaps are strategically timed. Hospitals can cope with daily peak overloads, the communication between consecutive shifts is improved and overtime is reduced. Hung allows 'downward' substitution in order to fill shortages for certain skill categories. The approach provides a permanent-shift system; this is a schedule in which nurses do not rotate. The advantages are that the people who work at the same time form a real team. There are also benefits for the social activities of the personnel members. For the scheduling problem, it requires the consideration of days on and off only, which reduces the complexity of the problem considerably. The constraints on the algorithm are coverage constraints and some time-related constraints: three free days per week and at least a number of free weekends per set of weeks. The algorithm is simple enough to enable a roster to be generated by hand. Some 
results are presented for problems in which the daily personnel requirements are not constant. The schedules match cyclical schedules to a high degree.

Hung (1992) identified the limitations of a cyclical approach. Cyclical schedules can only operate under the conditions of relatively stable demand and low variability, and they assume that sufficient workers can be recruited to staff the unpopular shifts. We believe that cyclical scheduling has many advantages but it is not directly applicable to many modern real nurse rostering situations. It might be a good idea to translate some of the benefits of cyclical scheduling into constraint based methods. Indeed, cyclical personnel rostering problems are generated using constraint satisfaction by Muslija, Gaertner, and Slany (2000), and applied on real world examples (see also Section 3.3). The approach allows for the implementation of personal preferences but there is no evidence that it is applicable to large and complex problems.

Tour scheduling is a special case of cyclical scheduling. The tour scheduling problem is one of simultaneously determining days worked, start times and shift lengths worked over some planning horizon. By redefining traditional work weeks for nurses, many hospitals implemented new nurse schedules (or tours). As an example, alternative scheduling patterns (ALTOURs) were introduced in the work of Easton, Rossin, and Borders (1992) that has already been discussed in Section 2.2.

Bechtold and Showalter (1987), combine the problem of staffing and scheduling personnel in a tour scheduling model. A similar example of a tour scheduling approach is presented in Bechtold, Brusco, and Showalter (1991). Compared to flexible nurse rostering, the problems tackled with tour scheduling adopt many simplifications which restricts the opportunity for application in modern hospitals.

Although they can easily be generated and cover the personnel requirements, cyclical schedules are not flexible when it comes to addressing slight changes in personnel demands or in expressing personal preferences. Cyclical scheduling is only applicable in very rare cases. Moreover, personnel seem to prefer 'ad hoc' schedules. Such schedules address fluctuating hospital demands in addition to flexibility with respect to the private preferences of the personnel.

\section{NURSE ROSTERING APPROACHES}

This section will present and discuss the key approaches to the nurse rostering problem that have appeared in the scientific literature. The papers are grouped according to the type of method that is described.

Since the 1960's many papers have been published on various aspects of computerised healthcare personnel scheduling. Most mathematical scheduling approaches make use of an objective function which is optimised subject to certain constraints. Early papers (Miller, Pierskalla, and Rath, 1976; Trivedi and Warner, 1976; Warner, 1976; Warner and Prawda, 1972) are nearly all examples of optimising scheduling algorithms. Researchers attempted to develop linear models for the problem. When it comes to applications in practice, there are just a few papers (see below) which describe the implementation of traditional mathematical algorithms on hospital wards. As we have already established in Section 2, most nurse rostering problems are extremely complex and difficult. Tien and Kamiyama (1982), for example, say that nurse rostering is more complex than the travelling salesman problem. For most real problems, the goal of finding the 'optimal' solution is not only completely infeasible, it is also largely meaningless. Hospital administrators want to quickly generate a high quality schedule that satisfies all hard constraints and as many of a wide range of soft constraints as possible. 
Several heuristic methods have been developed for solving real world problems (e.g., Anzai and Miura, 1987; Blau, 1985; Blau and Sear, 1983; Isken and Hancock, 1991; Kostreva and Jennings, 1991; Randhawa and Sitompul, 1993; Smith, Bird, and Wiggins, 1979; Smith, 1979; Smith and Wiggins, 1977). These are discussed in some detail later on in this article. Wiers (1997) discusses the applicability of operations research and artificial intelligence techniques for practical applications. Although cyclical schedules are generally considered to be less difficult to generate, most of them are constructed with heuristic techniques. In the 1980's and later, artificial intelligence techniques for nurse scheduling (declarative approaches, constraint programming, expert systems) were investigated with some success. Some of these approaches are still relevant to today's research issues (Chan and Weil, 2001; Chiarandini, Schaerf, and Tiozzo, 2000; Meyer auf'm Hofe, 2001).

Many of the most recent papers (1990's and later) tackle the problem with metaheuristic methods. All of these approaches are discussed below.

\subsection{Optimising approaches: Mathematical programming}

Mathematical programming methods are appropriate for finding optimal solutions. However, their major limitation is that they are simply not appropriate (at least, on their own) for the enormous and complex search spaces that are represented by modern nurse rostering problems. Most researchers restrict the problem dimensions and consider a small set of constraints in their models. These models tend to be too simple to be taken into a real modern hospital situation.

As mentioned above, most of the mathematical approaches are based on optimising the value of a single objective function. However, a number of experiments have also been carried out with goal programming or multi objective decision making.

\subsubsection{Linear and integer programming.}

Abernathy et al. (1973), isolated nurse scheduling from the general staffing problem and solved it using mathematical (stochastic) programming techniques. They divide the staffing of hospitals into three decision levels: policy decisions (including the operating procedures for service centres and for the staff-control process), staff planning (including hiring, discharge, training and reallocation), and short-term scheduling of available personnel subject to the constraints imposed by the first two stages. Even the short-term scheduling in Abernathy et al.'s work involves more management decisions than the nurse rostering problem. The number of people required to fulfill the stochastically varying personnel demands is not pre-determined in Abernathy et al.'s paper. Specific skills have to be considered, unlike in other work environments where the quality of the work is less dependent on the person. The solution has an iterative and a non-iterative part.

The approach has only been applied to a hypothetical example application. Assignments of individual nurses to shifts happen on a day to day basis. We believe that this early paper's contribution is that it provides a very nice framework upon which future researchers have posed more detailed and realistic problems.

Warner and Prawda (1972), presented a mixed-integer quadratic programming formulation to calculate the number of nurses from a certain skill category to undertake a number of shifts per day. Three non-overlapping shift types of 8 hours each are used. The goal function aims at minimising the difference between a given lower limit for the number of nurses and the variables (which represent the number of nurses). By adding nursing time (i.e. employing more people), the 
cost for personnel shortage can be reduced (never below zero, however). The minimum staffing requirements should consider the possibility of replacing personnel members with different skills and the organisation's established standards.

In our opinion, this early approach cannot address the current needs of hospitals. There is no possibility of including personal preferences in the model. All the nurses are anonymous. An excess of nursing supply for a particular skill category can absorb (at some suitable rate) the shortage of other skills. A drawback of the approach is that an accurate forecast of personnel demand cannot be trustworthy for a period which is longer than four days.

Warner (1976), elaborates on the previous formulation (Warner and Prawda, 1972) by introducing weights or fairness levels. He works with shift patterns of 2 weeks length, with a fixed day and night rotation but which respond differently to some flexible constraints. Nurses and entire wards distribute a number of 'penalty weights' to constraints and thus to patterns and schedules. Certain parts of the scheduling are carried out manually before the optimisation starts: weekends are assigned by hand and there is also a manual determination of people who will rotate. This simplifies the model. The mathematical programming algorithm consists of 2 phases: a search for feasibility and an improvement of the objective.

Even if the automated scheduling is not fully realised, this is a very interesting early contribution. One of the major benefits of the presented model is that it allows for a very fair evaluation of the obtained schedules. At the time of the publication (1976), the algorithm was implemented in several hospitals in the United States.

Trivedi and Warner (1976), describe a branch and bound algorithm to arrange the short-term assignment of nurses from different units (called 'float' nurses) whenever there is a shortage of personnel. These mathematical approaches cope with small-scale problems only and as such are not really relevant to the modern nurse rostering environment. However, this is one of the first papers to specifically discuss the concept of float personnel and which has formally modelled the idea. The employment of floating staff still plays a major role in modern hospitals. There does not currently exist a methodology to deal effectively with floating staff and this is a possible area of future research. Our experience of implementing our system in over 40 hospitals in Belgium is that (at least in the Belgian case), float nurses quickly seem to 'settle down' in a ward with a temporary shortage of personnel instead of remaining available for the entire hospital.

Apart from presenting an interesting overview of automated nurse scheduling in the US, Warner, Keller, and Martel (1990), also present a nurse scheduling system called ANSOS. The system consists of four important modules:

- The Position Control Module maintains essential scheduling information for each employee (e.g. skills, types of shifts, weekends off/on, maximum work stretch and overtime start).

- The Scheduling Module uses information such as holiday requests and personal preferences, but also hospital, unit, and employee-specific rules to generate schedules. The module is based on a mathematical programming model and it produces schedules in a few minutes time. Interactive scheduling is carried out by adapting the weights and starting the scheduler again.

- The Staffing Module computes the required staffing levels for each unit, based on patient needs and sick calls, for example. The results are compared to the scheduled staffing levels. Inter-unit assignment changes can solve problems of over- and understaffing.

- The Management Reporting Module provides a large number of reports, which is essential for applicability in practice. 
ANSOS takes a large number of individual constraints and preferences into account and it is applied to solving real problems in different hospitals (over 750 hospitals at the time of publication of Warner, Keller, and Martel (1990)). This paper represents an important contribution to the literature.

Miller, Pierskalla, and Rath (1976), formulate the personnel requirements in terms of minimum and preferred number of personnel per day, without specifying shifts. Staffing coverage and time related constraints with individual preferences are weighted against each other. Compared to Warner's approach (Warner, 1976), the number of unwanted shift patterns is much higher, thus reducing the complexity of the problem. The time related constraints are divided into two groups: the feasibility set and the non-binding constraints. Most of the non-binding constraints are stricter versions of already existing feasibility constraints. Apart from the objective penalty assigned to a violated constraint, an extra weight is added reflecting the nurse's personal perception of that violation. Miller et al. even introduce an 'aversion' index, which is a measure of how good or bad this particular nurse's schedules have been in the past. When granted, personal preferences cancel the violated binding constraints out. They reduce the number of possible patterns, and thus the search space, even further.

A cyclic coordinate descent algorithm is applied to look for a nearly optimal solution. A comparison with a branch and bound algorithm demonstrates that the algorithm by Miller et al. requires a much lower calculation time. However, the contribution of this early paper (in a modern context) is rather limited. The problems are very basic and the obtained solutions are not always feasible. Some schedules are under- or overstaffed on certain days of the planning period. However, it is worth pointing out that this particular difficulty does often occur in practice.

Bailey and Field (1985), formulate a general mathematical model for the nurse scheduling problem. The cost function in their definition is the sum of the cost for utilising a shift type multiplied by the number of occurrences of that shift type in the schedule. Bailey and Field identify schedules minimising cumulative costs. Choosing one schedule out of the set can be done manually or by a linear program. Bailey and Field reduce idle time in schedules and they propose a 12-hour scheduling period instead of a traditional 8-hour period. Although the approach cannot address the current needs of today's hospitals, it is one of the few published models that allow shifts to begin at any time during the day.

Rosenbloom and Goertzen (1987), developed an integer programming algorithm for cyclical scheduling. The approach consists of three stages. A set of possible schedules is generated in the first stage. The resulting schedules are evaluated with respect to work regulations and work patterns. In the second stage, the minimum daily coverage constraints are solved with an integer program. The third stage converts the solution into work patterns for each nurse. Even though optimal solutions are generated, the approach only considers work stretches and days off. In the modern hospital there is a large range of constraints and requirements which mean that the possibilities of directly applying the work described here are limited.

Jaumard, Semet, and Vovor (1998), propose an exact solution approach for a flexible realistic model of the nurse scheduling problem. The generalised linear programming model applies column generation and branch and bound. It allows full exploration of the set of feasible solutions. The authors claim that their model is more flexible to address changes in the scheduling environment than a heuristic model is. In practice, though, the conflicting nature of the nurse scheduling constraints makes it very difficult to find feasible solutions. The objectives include coverage constraints, salary costs, and care quality (balance between experienced and less experienced nurses). The approach is among the few that allow for formulating coverage constraints in terms of time intervals. However, 
a simplifying assumption of the model is that the demand periods are appropriately decomposed into smaller periods so that a given shift covers a given demand period entirely or not at all. This makes it less flexible than the model that is presented in Burke et al. (2001c). Over- and understaffing is to be minimised but there is a pool of float nurses available when the coverage is not met. Preliminary tests have been carried out based on real data from a large hospital and the results are approved by head nurses.

Millar and Kiragu (1998), combine all the possible 2-shift patterns of 4 days length for cyclic and noncyclic nurse scheduling. They construct a network whereby each node represents a feasible pattern and they solve it with an algorithm based on the MIP solver in CPLEX. However, the proposed patterns do not deal with many of the requirements that are needed in large hospitals.

Isken (2004), developed an implicit tour scheduling model that is part of a scheduling analysis tool for staff in a large US hospital. It tackles real hospital scheduling problems that, without the tour types, would be too large for mathematical programming techniques. The main goal of the approach is to reduce labour costs while meeting the fluctuating coverage requirements over a one week planning period. This is reached by determining shift start times and daily patterns. The implicit model includes full time and part time tours. It also allows for assigning different shifts throughout the week and for flexible starting days (of the tours). The model is more sophisticated than that described by the same author in Isken and Hancock (1991), (see Section 3.5.1). After solving the tour scheduling problem with a mixed integer programming solver, a post-processing step considers the assignment of shifts to patterns, without changing the obtained value of the objective function.

Moz and Pato (2004), tackle the very interesting and important problem of re-rostering nurse schedules. Many other researchers solve this problem by assigning float nurses, but Moz and Pato search for replacements within the ward. The models are based on a real hospital case. Apart from keeping the hard constraints satisfied, they aim at minimising the difference between the original schedule and the newly generated one, in order not to disturb the private life of the staff unnecessarily (as in Burke et al., 2001a; Burke, De Causmaecker, and Vanden Berghe, 1999; De Causmaecker and Vanden Berghe, 2003). Two integer multicommodity flow models are introduced, in which only the hard constraints are taken into account. A roster for $n$ nurses is presented as an $n$-commodities binary flow in a multi-level network. The second model resembles the first but equal shifts are aggregated in one node. The results obtained by the aggregate model are much better. Further research aims to incorporate the soft constraints into a multi-criteria model.

\subsection{Goal programming/Multi-criteria approaches}

Mathematical programming techniques are not always flexible enough to cope with relative ranking assigned to various goals. They are often restricted to optimising one single goal or criterion. Goal programming defines a target level for each criterion and relative priorities to achieve these goals. The method aims at finding a solution which is as close as possible to each of the targets in the order of the priorities given. Most of the papers discussed in this section apply mathematical programming but the latest modern research (Berrada, Ferland, and Michelon, 1996; Burke et al., 2002; Jaszkiewicz, 1997) tackles metaheuristics within a multi-objective framework.

Arthur and Ravindran (1981), propose a two phase goal programming heuristic for the nurse scheduling problem. They aim simultaneously to minimise (in priority sequence) staff size, the number of staff with ungranted requests or preferences, staff dissatisfaction, and the deviation between scheduled and desired staffing levels. A zero-one goal programming approach is used to 
assign days on and off to nurses. The shifts are heuristically assigned to the personnel members at the end of the scheduling process. Just like the mathematical approaches discussed in the previous section, the rather simple problem definition of Arthur and Ravindran (1981) limits the scope of directly applying the method to the real world problems encountered in more recent publications. Musa and Saxena (1984), propose an interactive heuristic procedure for solving the nurse rostering problem. Users can change the relative weights given to the goals during the scheduling process, in order to take special temporal conditions into account. We believe that the latter feature is an important contribution. It serves the needs of modern hospitals because the scheduling circumstances change regularly and are very hard to model mathematically. With a two week planning period and one single shift to be scheduled, the complexity of the tackled problem remains rather low. The approach will not be directly applicable to most practical nurse rostering problems but it may well be worth investigating whether some of the ideas could be incorporated into modern methods.

Ozkarahan and Bailey (1988), define three basic objective functions for their goal programming approach. The first goal is to minimise the deviation between the number of nurses scheduled and the demand, for each period of the day (called time-of-day scheduling). The second goal minimises the deviations between the sum of days on work patterns and the size of the work force (called day-of-week scheduling). With this goal, the system tries to schedule people according to their contract or work agreement. The third goal combines the day-of-week and time-of-day scheduling problems. Since the computational size of the studied problems is very large, they suggest the division of the work into two phases: one to determine schedules for the day-of-week and time-of-day schedules and one to assign people to the proposed schedules. By employing a heuristic assignment of schedules, the algorithm solves the most important shift times and days for individual nurses. Ozkarahan (1991), presents a goal programming approach for a decision support system. The model aims at maximising the utilisation of full time personnel, minimising over- and understaffing, and minimising several kinds of personnel costs. It provides support for staffing decisions and for nurses' preferences. In comparison with the other problems discussed in this review (see the tables of comparison in Appendix B), the problem dimensions are very small. Ozkarahan (and Bailey) presented a very comprehensive linear model for nurse rostering (and partly also for staffing). The problem had to be decomposed in order to reduce the dimensions but applications are still limited to small size problems.

Franz et al. (1989), developed a multi-objective integer linear program for health care staff working at different locations, called multi-clinic health regions. The problem involves staffing of personnel with varying skills, minimising travel costs and maximising the quality of service by considering personal preferences in addition to personnel requirements. Franz et al. developed a general optimisation approach, covering decisions at higher levels than short-term scheduling only. This contribution does not investigate the nurse rostering aspect in as much detail as other researchers do (see Appendix B).

Chen and Yeung (1993), combine goal programming with expert systems. The assignment of shift types to personnel members is carried out by the expert system part of the approach (see also Section 3.3). Goal programming assists in satisfying the time related constraints on personal schedules and attempts to cover personnel demands in the meantime. This paper represents a particularly interesting contribution because it does not attempt to strictly capture all the problem characteristics but it allows for flexibility and the relaxation of constraints.

Berrada, Ferland, and Michelon (1996), combine a multi-criteria approach for the nurse scheduling problem with tabu search (see also Section 3.4) in a flexible tool. In order to obtain a feasible solution, a set of hard constraints, related to administrative and union contract specifications, 
must be satisfied. A comprehensive list of soft constraints is treated as a list of goals to be reached and the overall objective is to get as close as possible to these goals. Every nurse works the same shift all the time. This implies that the problem can be split into 3 single-shift problems of reduced complexity. Short-term requests of individual nurses are easier to implement and the scheduling problem remains simple. The approach produces satisfactory results after some tests on a few real problems. In order to really assist head nurses and save time, a software system should be developed in which it is possible to modify the weights for the different objectives. This paper makes an interesting contribution because it is one of the first papers in which metaheuristics are applied to address a range of different goals.

Jaszkiewicz (1997), introduces a decision support system for the nurse scheduling problem in Polish hospitals. Working days and free days are preferably grouped, the number of shift changes on consecutive working days should be minimised, and shifts have to be divided evenly among nurses. The problem is solved in two stages. In the first stage, a simulated annealing approach is applied in combination with a multi-objective algorithm (called Pareto-Simulated Annealing) in order to generate a set of good quality solutions. The samples are work stretches which meet the objectives in a satisfactory way. A hospital planner evaluates these results in an interactive way in the second phase.

It is unavoidable in practical nurse rostering environments to have an interactive planning module and Jaszkiewicsz has made that possible in his system and it is actually applied in a hospital. This makes the contribution an important one. However, the model takes many constraints for granted, which in our opinion, probably means that this system would require further work in order to be easily transferred to other hospitals. The Tables 13-20 in Appendix B, indicate that the work described in Jaszkiewicz (1997) appears among the less flexible approaches (with set values instead of user definable parameters).

Burke et al. (2002), present a new multi-criteria approach after having implemented mainly cost function driven (Burke et al., 2001b) metaheuristics for nurse rostering in Belgian hospitals (see also Burke et al., 2001a, 2003, Burke, De Causmaecker, and Vanden Berghe, 1999 in Section 3.5). The criteria space, in which there is a criterion for each time-related constraint, is mapped to a preference space with dimensionless units. Previously developed heuristics (Burke, De Causmaecker, and Vanden Berghe, 1999) guide the search in this new solution space. One of the major advantages of this approach is the possibility for users to express their preference for certain constraints, instead of having to set very abstract cost parameters. The weights can control the compensation of constraints. A major advantage of the multi-criteria method is that it facilitates a better handling of dissimilar constraints by taking the possible ranges for the criteria into consideration. The method requires further development (to handle the full range of constraints required by hospitals) before it could be taken directly into a hospital ward.

Most mathematical approaches apply exact methods to find a feasible set of schedules. However, the real world problem is so complex that almost all the publications mention heuristic methods to assign work patterns to people and to cater for personal preferences requirements.

\subsection{Artificial intelligence methods}

\subsubsection{Declarative and constraint programming}

Okada and Okada (1988), presented a formal core method in Prolog which assists in the assignment of shifts to nurses. The relative significance of various requirements can change during the 
planning period. Not all of the constraints have to be strictly satisfied. Okada and Okada find it even hard to define what an optimal schedule is. They distinguish between the scheduling task and the general requirements that must be fulfilled. The approach is much stricter than most others, the references appear in the 'set value' colums of Tables 13-20 in Appendix B. This paper represents a very systematic method to assign shifts whereas in approaches that are better suited for general application (Burke et al., 2001a; Meyer auf'm Hofe, 1997, for example), nearly anything can be scheduled and a penalty cost will be generated for the violated constraints. Assignments are carried out in a manual-like manner, following a strict procedure which is visible in the 'general requirements'. Okada (1992), elaborated on the general scheduling procedure presented in Okada and Okada (1988) in order to develop a system that can handle varying institution-specific requirements. A declarative program, generated through an interview with the user, models institution-specific information. The method represents a set of 'role sequences' as a language, in which the constraints are presented as a grammar. Individual preferences are then constraints on strings. It is, in our opinion, a very unique and interesting way to formulate the problem and it might be useful for setting up a formal description of nurse rostering problems. There are multiple criteria to evaluate the possible schedules for personnel members. By taking them all into account, the system tries to discover the 'best' schedules. The problem dimensions are comparable to those of Okada and Okada (1988) but there is an extra skill category, consisting of two leaders. Okada's system allows for a flexible definition of the soft constraints by the users of different types of hospitals.

Weil et al. (1995), reduce the complexity of a constraint satisfaction problem by merging some constraints and by eliminating interchangeable values and thus reducing the domains. It is a sensible way of simplifying a problem and, although the generic model can cope with different legal regulations, Weil et al. solve quite straightforward problems with it.

Darmoni et al. (1995), describe a software system called Horoplan for scheduling nurses in a large hospital. Apart from rostering, the system also covers some short term staffing decisions. It is fit for use in practice but it does not seem to facilitate very flexible problem definitions. Horoplan generates nursing schedules by applying a step by step procedure. It makes use of a constraint based programming tool called Charme. We assume that this sequence of steps reflects the way that head nurses create their schedules manually.

Meisels, Gudes, and Solotorevski (1995), combine constraint networks and knowledge-based rules to solve employee timetabling problems. The described approach is implemented in a commercial software package, called TORANIT, which is particularly flexible with respect to defining constraints and shifts. It cannot guarantee optimal timetables because of the complexity of the allowed formulations. Compared to the constraint satisfaction approaches discussed above, we consider this as an advantage. Optimal schedules are of no avail anyway if the problems are dynamically changing as circumstances change. For the constraint programming approach, constraints fall into 3 groups:

- Mutual exclusion constraints: nurses can be assigned to one job at a time.

- Finite capacity of employees: for example: a limited number of daily/weekly/monthly working hours, a limited number of night shifts per employee.

- Objectives: constrain the distribution over time of employee assignments per shift.

The rule-based part of the system combines assignment rules and constraint rules, which are representations of human knowledge. Personal preferences for certain shifts are tackled by the assignment rules. This constraint orders assignments by preference, e.g. morning shifts preferred to late shifts. The constraint rules handle the demand for certain types of nurses or for individual 
nurses, in addition to personal constraints. Meisels et al. conclude that generic non-binary constraints in constraint networks and the ordering of constraints in line with their preference are very efficient to solve the constraint networks. Meisels and Lusternik (1998) also investigate constraint networks for employee timetabling problems. Just like in Meisels, Gudes, and Solotorevski (1996), a flexible problem formulation should be possible. The approach consists mainly of standard constraint processing techniques, which solve randomly generated test problems. Experiments show that the domain size of the variables in the constraint networks is a critical factor for solvable problems. Such solutions do not necessarily exist in real life and constraint satisfaction techniques may not be the most convenient ones to handle infeasibility. Meisels and Lusternik also tested a genetic algorithm and found the same results.

Cheng, Lee, and Wu (1997) developed a nurse rostering system for solving one particular hospital problem. They make use of the ILOG solver for generating a schedule that satisfies a large set of rules (such as preferred consecutive patterns and shift balance among nurses). The rules are divided into hard and soft constraints. Solutions are generated with a 4 step procedure, that is specifically oriented towards solving the particular problem (see also Cheng, Lee, and Wu, 1996). This contribution is less generic because of the problem specific modelling but nonetheless, it has been applied in a real modern hospital and as such it represents a significant relatively recent addition to the literature.

Meyer auf'm Hofe (1997), presented the nurse rostering problem as a hierarchical constraint satisfaction problem. His research resulted in the development of a library containing various search algorithms and constraint propagation techniques. All of this is part of a nurse scheduling system (called ORBIS Dienstplan), which is tested on complex problems in hospitals and fire departments. The model provides the possibility of flexibly defining personnel requirements, provided that they are expressed in terms of shift types. It enables the use of arbitrary sets of shifts, by adding additional overlapping shift types to the traditional early, day and night shift. Generated schedules also have to meet requirements like: legal regulations, personnel costs, flexibility with respect to the actual expenditure of work, and the consideration of special qualities. Some of the previous considerations belong to a higher decision level than the pure short time rostering that is the subject of this review paper. It is not clear, however, how staffing decisions are implemented in the model. They might be also just input data. Work regulations determine to which extent requirements can be fulfilled, taking different skill categories into account. The software offers users the possibility of adapting it to their own needs. It enables the definition of work regulations and Meyer auf'm Hofe mentions qualified and experienced personnel but it is not clear how the system deals with them. The time related constraints are less general than in Burke et al. (2001b), for example, but they certainly belong to the most applicable of the published approaches. It is impossible in practice to satisfy all the constraints; Meyer auf'm Hofe therefore mentions 'partial' constraint satisfaction. Consequently, requirements are treated in order of importance. It is a very complex task to generate a satisfactory schedule in practical personnel planning situations, but the method is interactive and the user can alter the result of the algorithms by hand. The proposed approach is much more flexible and suited for real problems than many of the previously discussed papers in this review. Meyer auf'm Hofe (2001), builds on his previous research and on experiences of the software system (Meyer auf'm Hofe, 1997), which is used in practice. The generic model is developed for use in different real world personnel rostering settings. Hierarchy levels and constraint weights are defined. Instead of considering it as constraint satisfaction, nurse rostering should rather be looked at as constraint optimisation because it is not possible to satisfy all the constraints anyway. Fuzzy or 'non-crisp' constraints are introduced as constraints that can 
be partially violated and partially satisfied. A hybridisation of iterative improvement and branch and bound are used in a constraint propagation algorithm that deals with the fuzzy constraints. It is robust enough to handle varying formulations of the nurse rostering problem. We consider Meyer auf'm Hofe's work to represent a major contribution to modern nurse rostering research.

Abdennadher and Schlenker (1999a, b), present an interactive program that is based on constraint programming. The system has been tested in a real hospital environment. In the papers, the authors say that INTERDIP was presented at a computer exhibition and that several companies were interested in marketing it. However, as far as we are aware, nothing has been published since and (although we have searched extensively), we have been unable to determine what happened to the software.

Muslija, Gaertner, and Slany (2000), tackle a different goal from the above described constraint satisfaction approaches. They attempt to generate cyclical solutions for a simplified version of general workforce scheduling problems. Rotating workforce schedules are beneficial for the employees' health and satisfaction, and thus increase the work performance of the personnel. Muslija et al. generate allowed (satisfying legal constraints) shift sequences in a one week planning period. Certain coverage levels must also be guaranteed. Important characteristics of schedules are the length of work blocks and 'optimal' weekend characteristics. Even when generating this type of rotating schedule, personal preferences and extra constraints can be implemented. The proposed method can assist in calculating good schedules very quickly but is probably too simplified to be of use in large scale healthcare environments.

Li, Lim, and Rodrigues (2003), apply a hybrid constraint satisfaction/local search technique to a problem that was derived from a real world hospital situation. Hard constraints include coverage constraints and some of the time related constraints on personal schedules. The soft constraints are called preference rules and they mainly consist of personal preferences or general preferences for shift sequences. Li et al. first solve a subproblem, in which some of the constraints are relaxed, with constraint satisfaction. After that they apply local search techniques to improve the solution by attempting to satisfy as many preference constraints as possible.

\subsubsection{Expert systems and knowledge based systems}

Expert systems approaches provide the possibility for developing user-interactive, integrated (staffing, rostering) decision support methodologies for nurse scheduling problems (Nutt, 1984).

Smith, Bird, and Wiggins (1979), developed a 'what-if' decision support system for various sets of weights instead of providing optimal solutions. A very nice feature of this early paper is that the software is interactive and that it allows users to assign weights to different objectives and to take personal preferences into account. The time related constraints are kept basic, which limits the system's applicability to modern general problems.

Bell, Hay, and Liang (1986), developed a visual interactive decision support system for workforce scheduling. It is a rather basic solution but it is interesting because of the levels of interaction.

The decision support system introduced by Ozkarahan, (1991), makes use of a goal programming model (see also Section 3.1). The problem dimensions are kept very small. We can state that other problems discussed in this review (e.g. Burke et al., 2001a, 2001c; Burke, De Causmaecker, and Vanden Berghe, 1999; Jaumard, Semet, and Vovor, 1998; Meisels, Gudes, and Solotorevski, 1996; Meyer auf'm Hofe, 1997) would be far too complex to be tackled with the proposed method. Ozkarahan and Bailey (1988) describe three objectives in the goal programming approach (see Section 3.1). 
Chen and Yeung (1993), schedule full time nurses with a hybrid expert system approach (see also Chen and Yeung (1992)). The system handles constraints such as requested days off, maximum consecutive working days (restricted to 6), minimum consecutive free days, avoiding on/off patterns and minimising overtime. Some other fairness measures are also taken into consideration. In the meantime, the program attempts to meet minimum staff levels by applying a goal programming module. Unlike in many other approaches, where minimum coverage is a hard constraint, Chen and Yeung define aspiration levels for each goal. Minimum staffing requirements on particular days can thus be relaxed.

The expert system itself is involved in assigning early, late and night shifts. The other problem dimensions are very small compared to models that are also oriented towards assisting schedulers in practice. All the personnel members have the same work regulation and the same skill.

Scott and Simpson (1998) reduce the global problem search space by incorporating constraint elements in a case-base. They attempt to generate good quality solutions within a limited time scale by mimicking the approaches of manual roster planners. Scott and Simpson identified the following steps in creating a case-base solution for the problem:

- Set up a case-base of sets of efficient shift patterns

- Analyse the (partial) problem and find the best case match

- Allocate shift patterns from the selected case to the nurses using an ordering rule

- Analyse shift allocation to find coverage problems

- Fix, if possible, coverage problems by legal swaps of shifts

- Store the solution as a generalised case if it is sufficiently different from existing cases.

There is no report on results, the paper only describes the main ideas of the approach (see also Scott, 1998; Scott, Simpson, and Ward, 1997).

Petrovic, Beddoe and Vanden Berghe (2003), present a case-based reasoning approach to nurse rostering problems. They attempt to automate the self-scheduling approach that is now applied in a particular UK hospital. Rules that have to be considered when constructing a schedule are: providing the appropriate skill mix, meeting the coverage, staff-to-patient ratios, and a set of time related constraints. Hospital planners combine and repair partial rosters that have been constructed from the personal preferences and requests. It is interesting that the methodology imitates the human style of reasoning in which problems are solved using past experience, on the premise that similar problems require similar solutions. The main ideas are comparable to those of Scott and Simpson (1998) but this paper also provides results of tests carried out on real data.

\subsection{Heuristics}

In practice, the size of nurse rostering problems, and the lack of knowledge about the structure of most of them, hinders the applicability of exact optimisation methods. Many heuristics have been developed to obtain high quality schedules for real world problems in an acceptable computation time, without an explicit mathematical model.

The applicability of heuristic scheduling algorithms requires a clear formulation of the hospital requirements. It is necessary to quantify the quality of different schedules in an unambiguous way. Heuristic schedulers outline a number of steps in order to generate a schedule which respects the constraints (e.g. Randhawa and Sitompul, 1993). Most heuristics are developed for generating cyclical schedules and they often emulate the trial-and-error manner whereby the planner 
constructs the schedule by hand. In this section, most of the contributions consider metaheuristics, which represent some modern attempts to solve complex scheduling problems.

Smith (1976), presents an interactive algorithm which helps the scheduler to construct a cyclical schedule. The algorithm takes coverage constraints and days off policies into account and it determines the number of personnel members, which is a staffing decision. Not all the staff members can have rotating schedules, however. In view of more recent developments in nurse rostering, this early heuristic for cyclical schedules cannot really be considered for practical use today. Smith and Wiggins (1977), developed a software system, using list-processing techniques that generate non-cyclical monthly schedules for several skill categories, which allows for different kinds of part time work. Schedules are developed per person, meeting the staffing requirements by alternating days off. This is more similar to short term nurse rostering than Smith's earlier work (Smith, 1976) and it also abandons the cyclical solutions. The model incorporates a considerable number of constraints: patterns, days off. It also allows the specification of the type of leave, which is an interesting feature for nurses that is rarely taken into consideration in the models that we have reviewed in this article. Another positive feature is the interactivity of the system. Users can make manual changes to the generated schedules.

Blau and Sear (1983), generate all the possible shift patterns in a two week period. They evaluate them with respect to the nurses' preferences. A cyclic descent algorithm is used in the second step in order to find an optimal overall schedule with one of the 60 best patterns for each nurse. The approach is developed for wards with three skill categories in which substitutability is hierarchical. Both the problem and the model are comparable to those presented by Aickelin and Dowsland (2000) and Dowsland (1998) (discussed in Section 3.5). However, Blau and Sear take over- and understaffing into account whereas Aickelin and Dowsland consider solutions with coverage deficiencies as infeasible. The contributions in Aickelin and Dowsland (2000) and Dowsland (1998) are also concerned with achieving optimality. Blau (1985), tries to equalise the distribution of unpopular work in addition to the frequency with which employees are granted requests for shifts or days. This is one of the earlier attempts (besides Warner's (Warner, 1976)) to evenly treat personnel with respect to workload and preferences. In later contributions (see also Table 18 in Appendix B), the distribution of work among people is often arranged via additional constraints.

Anzai and Miura (1987), present a cyclic descent algorithm for a ward in which the personnel members are identical (with respect to skills and work regulations). Anzai and Miura state that their model is too simplified for practical applications.

Kostreva and Jennings (1991), solve the nurse scheduling problem in two phases. Groups of feasible schedules are calculated in a first step. The groups respect the minimum staffing requirements and each individual schedule fulfils all major working constraints. In the second phase, the best possible 'aversion score', which is based on the preferences of the individual nurses (Kostreva and Genevier, 1989), is calculated. The tackled problems are not complex. All the skill categories are scheduled independently, which comes down to a decomposition into partial problems. Modern nurse rostering practice is not usually compatible with this type of approach.

Schaerf and Meisels (1999), present a general definition of employee timetabling problems. It is the problem of assigning employees to tasks in shifts. The shifts are predefined time periods that can reside anywhere on the time axis. The model includes strict coverage constraints but it allows flexibility with respect to time related constraints. The problem involves exactly meeting the coverage and a set of time related constraints, while trying to meet preferences in assignments. A general local search is introduced that allows partial assignments and thus makes use of a larger 
search space. The paper presents hill climbing algorithms for the local search. Each technique concentrates on a different part of the search space, denoting their 'steepness'. In the approach, the neighbourhood functions can include 'insert', 'delete', and 'replace' moves. The approach has been tested in theoretical environments: a hospital and a production environment. However, the flexibility towards satisfying coverage (partial assignments), is a very interesting step towards solving problems in practice. It has been rarely applied before (Burke et al., 2001c; Tanomaru, 1995) (see also Table 10 in Appendix B).

\subsection{Metaheuristic scheduling}

We believe that metaheuristics are generally better suited than most other approaches for generating an acceptable solution in cases where the constraint load is extremely high and indeed in cases where even feasible solutions are very difficult (if not impossible) to find. Since infeasibilities are often unavoidable in today's practice it is usually necessary to modify one's view of what is feasible and computer systems that cannot cope with this have a serious disadvantage.

\subsubsection{Simulated annealing}

Isken and Hancock (1991), belong to the rare group of researchers who allow variable starting times instead of 3 fixed shifts per day. They formulate the problem, which is (in other respects) rather simplified, as an integer program. Under- and overstaffing are allowed but penalised. We think that it is very relevant not to assume fixed shifts since many modern hospital activities incorporate flexible hours. Isken and Hancock thus solve a different problem than many other nurse rostering problems because of the flexibility in personnel coverage. Their model was never actually intended to address the nurse rostering problem. The model was a tactical tour scheduling model for addressing scheduling policy issues upstream from the short term timetabling problem (Isken and Hancock, 1998).

Brusco and Jacobs (1995), combine simulated annealing and a simple local search heuristic to generate cyclical schedules for continuously operating organisations. Apart from hospitals, many other organisations (including telecommunications, public safety, and transportation organisations) face demands for labour on a continuous basis-24 hours per day, 7 days per week. Commonly, organisations that must service continuous demand allow their workers' schedules to begin at any hour of the week. This problem is rather exceptional and makes the scheduling process far more complex than shift type rostering. The work concentrates on staffing by comparing the cost of alternative personnel scheduling options. Brusco and Jacobs call their problem a tour scheduling problem; it determines daily shift schedules and weekly days-off assignments for employees across a specified planning horizon. One of the most common flexibility alternatives for pure tour scheduling encountered in practical applications is the use of a mixture of both full-time and parttime workers (a mixed workforce). One such approach involves a problem reduction that prohibits the use of daily shift schedules that would overlap from one 24-hour period to the next. The mathematical problem associated with this reduction is referred to as the 'discontinuous tour-scheduling' formulation.

Although the paper is more oriented towards staffing, we found it an interesting contribution for several reasons: it deals with part-time work, the assignments are not restricted to predefined shifts, and the approach can tackle different kinds of real problems that need not be solved to optimality. 


\subsubsection{Tabu search}

Berrada, Ferland, and Michelon (1996) combine tabu search with a multi-objective approach (see also goal programming in Section 3.2). It is interesting that a metaheuristic is applied instead of a mathematical programming approach but we think that the problem is of relatively limited applicability in a real world situation because it looks only at switching days off and working days for different people.

Dowsland (1998), makes use of different neighbourhood search strategies in a tabu search algorithm. The heuristic oscillates between feasible solutions meeting the personnel requirements and schedules concentrating on the nurses' preferences. At any time of the planning period, the algorithm must provide enough personnel with the requested qualities, while satisfying the people by granting personal requests in a fair manner. The attractiveness of work patterns differs from person to person. Rather than designing a generic, widely applicable algorithm, the model was developed for solving the personnel scheduling problem in one particular hospital (see also Aickelin and Dowsland, 2000) and produces very good quality results for that data.

The paper is interesting because it enables the search to go back and forth from the feasible to the infeasible region, whereas other approaches (Berrada, Ferland, and Michelon, 1996; Burke et al., 2001a; Burke, De Causmaecker, and Vanden Berghe, 1999) tend to avoid infeasibility.

Dowsland and Thompson (2000), combine integer programming models with a modern heuristic to solve the same nurse rostering problem as in Dowsland (1998). The algorithms will be implemented in CARE (Computer Aided Rostering Environment), a commercial package for UK hospitals. It is notable that papers describing algorithms for real hospital use tend to cope with similar issues and come up with similar solutions. Just as in De Causmaecker and Vanden Berghe (2003), Dowsland and Thompson developed a pre-processing phase to investigate whether the available number of nurses is sufficient for covering the demand. In their paper, a knapsack model handles that part of the problem. It takes nurses' grades and contracts into account and supports the assignment of float nurses. After that phase, the tabu search algorithm described in Dowsland (1998) searches for a set of shift patterns. There is no further heuristic search required for finding the best allocation of early and late shifts since that can be modelled as a minimum cost flow problem in a closed network. The approach is particularly interesting in terms of practical use because solutions are obtained considerably faster than with an IP package. That is due to the reduced search space in the pre- and post-processing integer programming approaches.

Burke, De Causmaecker, and Vanden Berghe (1999) hybridise a tabu search approach with algorithms that are based upon human-inspired improvement techniques. Some of the hybridisations function as diversifications for the tabu search algorithm. A 'weekend step', for example, only attempts to solve some very specific soft constraints. Other hybridisation algorithms have been developed to provide a good quality roster that cannot be improved by small modifications. The details about changing the neighbourhoods during the search, and the benefits and limitations of a variable neighbourhood search approach, are explained in Burke et al. (2003).

The resulting model is applied in several very different Belgian hospitals and thus it is suitable for problems with varying specifications. Users of the software system can define their own shift types, work regulations, skill categories and replacement strategies between skills (substitutability among skill categories is personalised in practice), in order to meet the hospital requirements. Coverage (defined as minimum and preferred coverage) is treated as a hard constraint but there are many optional procedures to assist hospital planners in setting them (see also De Causmaecker and Vanden Berghe (2003)). While remaining in the feasible part of the solution space, the algorithms attempt to modify the roster in order to reduce the number of violations of time-related constraints 
on personal schedules. As is clear from Tables 13-20, the set of user definable constraints is very extensive. The time related constraints are divided into categories. Certain rules hold for the entire hospital. Underneath these global rules, each ward can define its own local rules. In Belgium there are many hospitals that allow for a personal work agreement per nurse. The presented model can handle that. Users can express personal preferences for certain shifts on certain days, and request days off easily. The model allows for selecting people who should preferably work together or preferably not. While evaluating the quality of a schedule, the previous planning period is also considered because there is an influence on the value of certain constraints. We believe that the nurse rostering problem tackled in Burke, De Causmaecker, and Vanden Berghe (1999) belongs to the most complex and flexible problems reported in the literature. Also, the model and algorithms are implemented in a system that has been used in over 40 Belgian hospitals. By automating the search for a solution, compared to a manual scheduling method, the approach of Burke, De Causmaecker, and Vanden Berghe (1999) reduces the calculation time and effort considerably and the resulting schedules are consistently better. An overview of our work in Belgian hospitals is presented in Burke, De Causmaecker and Vanden Berghe (2004).

Valouxis and Housos (2000), propose hybrid optimisation techniques for three-shift schedules. A list of feasible workstretches is enumerated by only looking at forward rotation. They integrate tabu search in an integer linear programming model. The complete model would be inefficient but the performance is improved by applying an approximate integer linear programming model. Better solutions are then generated by using local search techniques. In the neighbourhoods defined by the local search procedures, a tabu search algorithm is performed for finding high quality solutions.

Although there are more complicated problems in the literature, this approach takes some constraints into account that are particularly interesting for real nurse rostering problems. Examples are: balancing the workload among nurses, people can assign desirability to all the feasible workstretches.

Ikegami and Niwa (2003), introduce a mathematical programming formulation for the nurse scheduling problem in Japan and they solve the problem with metaheuristics. A large survey of 315 units in 23 Japanese hospitals revealed interesting data for the problem description. In Japan, rapid shift rotation is quite common, i.e. shifts are changing several times per week and therefore most existing models are not applicable. The presented model covers features such as different skill categories, personal preferences, taking the results from the previous planning period into account and balancing the workload. These are all characteristics that seem unavoidable for real world applications.

Ikegami and Niwa distinguish between nurse constraints (which we call time related constraints) and shift constraints (called coverage constraints in this review). They decompose the problem into subproblems in which the nurses' schedules (except one) are fixed. The algorithms attempt to repeatedly satisfy the constraints on different subproblems. Techniques are presented for 2-shift and 3 -shift problems only, although the model can handle a variable number of shift types. A tabu search algorithm generates good quality results for the 2 -shift problem in a reasonable amount of computation time. A branch-and-bound algorithm is presented for both the 2-shift and the 3-shift problem. It generates very promising results but extra heuristics are required to speed the algorithm up.

Bellanti et al. (2004), present algorithms for solving a particular problem in an Italian hospital ward. Tackling a real world problem, they deal with a large set of detailed constraints, which they divide into coverage constraints and contractual and operational requirements. Some unavoidable relaxations have been incorporated in the model, for example allowing a deviation between the 
coverage requirements and the actual number of scheduled nurses. The research has resulted in the development of a software system that is currently in use in the hospital. Its results improve upon those manually generated in the hospital and the computation time is acceptably low.

They describe in detail how initial solutions are constructed. By applying different multistart procedures, different initial solutions are generated, from which the best is taken for the local search procedure. A tabu search method and an iterated local search approach have been developed. Both techniques outperform a multistart local search approach and iterated local search seems to perform slightly better than tabu search.

\subsubsection{Genetic algorithms}

Easton and Mansour (1993), developed a distributed genetic algorithm for an employee staffing and scheduling problem called 'tour scheduling'. The algorithm aims at minimising the number of personnel members to fulfil the demands. The fitness function represents violations of constraints and individual solutions are improved with local hill climbing operators. The genetic algorithm works very well for a set of test problems but we think that the model is possibly too simple (e.g. no personal preferences) for real modern applications.

Tanomaru (1995), presents a genetic algorithm to solve a staff scheduling problem. The objective is to minimise the total wage cost in a situation where the number of personnel is not fixed. Solutions have to meet the total workforce requirements while respecting the maximum number of individual working shifts. Overtime is allowed, however. Although the problem dimensions are very basic, this is one of the few research papers which allow flexible starting times for the shifts. Solutions for the personnel are represented by 7 pairs of integers, giving the start and stop times per day. For real-life problems, Tanomaru concludes that his heuristic mutation operators might be too time consuming. Also, we doubt whether the model is general enough for real problems. The number of constraints that are tackled is very low.

Aickelin presented a PhD thesis on Genetic Algorithms for Multiple-Choice Optimisation Problems (see Appendix A). One of the two problems he discusses with respect to his method is a nurse scheduling problem. The same problem is tackled by Aickelin and Dowsland (2000), where the evolutionary approach is a complex 'co-operative genetic algorithm'. Problem specific knowledge is used both to guide the crossover operator and a hill-climbing operator within the evolutionary algorithm. Separate soft constraints on the personnel schedules are not evaluated. Aickelin and Dowsland determine the value or penalty of weekly schedules beforehand (this is similar to what Warner, 1976 does). Only a limited number of such patterns exist and instead of evaluating constraints, the values per pattern are determined and saved. Nurses' preferences can change, so a cyclic schedule cannot be generated to satisfy the requirements. In the presented approach, Aickelin tries to decompose the problem into 'easier to solve' sub-problems. Night and day shifts are preferably not combined in a personnel member's weekly schedule. Night shifts can be scheduled separately to a certain extent. The skill categories are handled in a hierarchical manner in that higher qualified people can replace lower qualified people. This is an important contribution and it works very well for the personnel scheduling problem of a particular hospital. However, it is not applicable to the situation in all hospitals. Indeed in some practical situations it is undesirable to allocate highly qualified senior personnel to tasks for junior nurses. It is also the case that scheduling night shifts separately is not in accordance with some hospital practices.

Aickelin and Dowsland (2003), apply an indirect genetic algorithm to the same nurse rostering problem as in Aickelin and Dowsland (2000). This enables them to better deal with the necessary constraints. The approach consists of an indirect coding and heuristic decoders. By applying a 
hybrid crossover operator and by intelligently reducing the search space, the results are further improved. The indirect genetic algorithm outperforms the results obtained by tabu search in Dowsland (1998) (see Section 3.5.2).

The problem tackled by Aickelin and White (2004), is exactly the same as the problem described in Aickelin and Dowsland $(2000,2004)$. The constraints are not expressed explicitly but there is a set of feasible shift patterns from which the assignments have to be chosen. Two different algorithms are introduced: a genetic algorithm with an encoding that is based on an integer programming formulation that is presented in the paper; and an 'indirect' genetic algorithm with a separate heuristic decoder function (as presented in Aickelin and Dowsland, 2000). Aickelin and White propose a statistical method for comparing algorithms, even for algorithms that do not always generate feasible solutions on a chosen problem instance. The comparison algorithm provides a method to discover better parameter settings or components that improve the results. By applying the comparison procedure, a heuristic has been built that performs better than all the algorithms developed in previous research. The method can also be applied to problems other than the nurse rostering problem.

An evolutionary approach called a population-less co-operative genetic algorithm is applied to solve another 3-shift problem by Jan, Yamamoto, and Ohuchi (2000). Feasible schedules satisfy the hard constraints, which are coverage constraints and personal requests for days off. The soft constraints are time-related constraints on personal schedules (a small subset of the soft constraints in Tables 13-20). A 15-days history of personal schedules is looked at for the evaluation. It is not clear how a feasible initial schedule is created. After the initialisation, the genetic algorithm searches solutions in the feasible region only. New schedules are generated by applying a two-point crossover on two personal schedules: the worst schedule and a randomly selected one. The search stops when a predefined number of generations is reached. Some optimisation methods have been explored: increasing the number of mates for crossover, diversification and the application of mutation and 'escape' operators. In order to make this approach applicable to real hospital problems, more realistic individual cost functions are required, in addition to an evaluation procedure for the hospital planner to estimate the quality of a schedule.

Kawanaka et al. (2001), propose a genetic algorithm for scheduling nurses under various constraints. A distinction is made between 'absolute' and 'desirable' constraints. Among the absolute constraints are the minimum coverage per skill category. The objective function considers weights for the desirable criteria: the balance of shifts, the granting of requested holidays, the number of night shifts assigned to unskilled, new nurses. Compared to a conventional method, which only implements the absolute constraints in the evaluation function, the presented approach generates considerably better results. Applying crossover to nurse rostering nearly always causes problems of infeasibility (see also Burke et al., 2001a). Kawanaka et al. overcome this problem by exchanging shifts while attempting to maintain the characteristics of the parents. Unfortunately, they do not explain what these characteristics are and how they identify them.

Burke et al. (2001a), elaborate on the problem described in Burke, De Causmaecker, and Vanden Berghe (1999) to address some of the shortcomings of the approach described there. They developed a set of genetic and memetic algorithms. Both types make use of a population of solutions but in the memetic approach, each of these individuals undergoes a local improvement before taking part in the recombination phase. The coverage constraints are satisfied throughout the search space. By simple recombination of two solutions it is nearly impossible to create a feasible solution and therefore repair procedures have been developed. The authors developed appropriate good quality schedule characteristics for inheritance to the next generation of solutions. 
The solutions are relatively unaffected by initialisation and parameter changes. Thanks to evaluating a population of solutions instead of one single solution as in Burke, De Causmaecker, and Vanden Berghe (1999), the new approach overcomes inappropriate choices for the planning order of skill categories. The approaches are particularly robust to handle the variety of instances that occur in the real world. Although the memetic approaches generally lead to an increase in quality, the drawback is a higher computation time when compared to the results of a single population approach (see Burke et al., 2003; Burke, De Causmaecker, and Vanden Berghe, 1999). Therefore, it is only applicable in practice when schedules are generated long before they are needed.

\section{CONCLUSIONS}

In this paper, we have briefly reviewed and discussed a wide range of nurse scheduling papers and articles that have addressed a broad spectrum of models, methods and approaches to the problem. Nurse scheduling has attracted the attention of scientists from operational research and artificial intelligence for about 40 years. The problem is of critical importance for a variety of reasons. The automatic generation of high quality nurse schedules can lead to improvements in hospital resource efficiency, staff and patient safety, staff and patient satisfaction and administrative workload. Researchers have constructed and addressed a wide range of nurse scheduling models which have represented many different versions of the problem. Many techniques have been developed and described in the literature. Appendix B is a classification of the key methods that have been presented over the years and the aspects of the problem that they address. These techniques have varied from being quite simple to being very advanced. However, one key point that can be drawn from an analysis of the literature over the years is that very few of the developed approaches are suitable for directly solving difficult real world problems. Many of the models that have been presented and discussed are too simple to be directly applied to hospital wards. This point is even more pronounced if we are to consider modern problems in large and busy hospitals. There is a definite gap between much of the current state of the art in nurse scheduling research and the demanding and challenging requirements of today's hospital environments. A crucial scientific goal for nurse scheduling research in the future is to fully address the needs and requirements of the real world. This goal has been addressed by several papers in the literature but there is still considerable scope for exploiting emerging technologies and providing the capability to develop a level of sophisticated decision support methodology that does not currently exist (see below). We illustrate the approaches that (if clearly verifyable in the literature) have been implemented in practice and those that have been tested on real world data in Table 1.

In the right hand column of Table 1, we illustrate the methods and approaches from the scientific literature that have been implemented in hospital wards. We have split these into those approaches that have been used in just one hospital and those that have been applied in more than one. This gives us some indication of the genericity of the methods/systems that have been applied in practice. The systems in the bottom right part of Table 1 (those that have been applied in multiple hospitals) represent the most flexible approaches that have appeared in the literature. The left hand column of Table 1 presents the papers that describe techniques which have been evaluated on real world data (but where there is no evidence that they have actually been used in practice). The nurse rostering approaches which do not address real problems and those which are only concerned with modelling issues are not included in this table. We have also not included those papers which deal with staffing issues (the stage before nurse rostering - see Section 2.2) because the focus of this paper is on rostering. It is important to note that we have constructed 
Table 1. Applicability of the approach

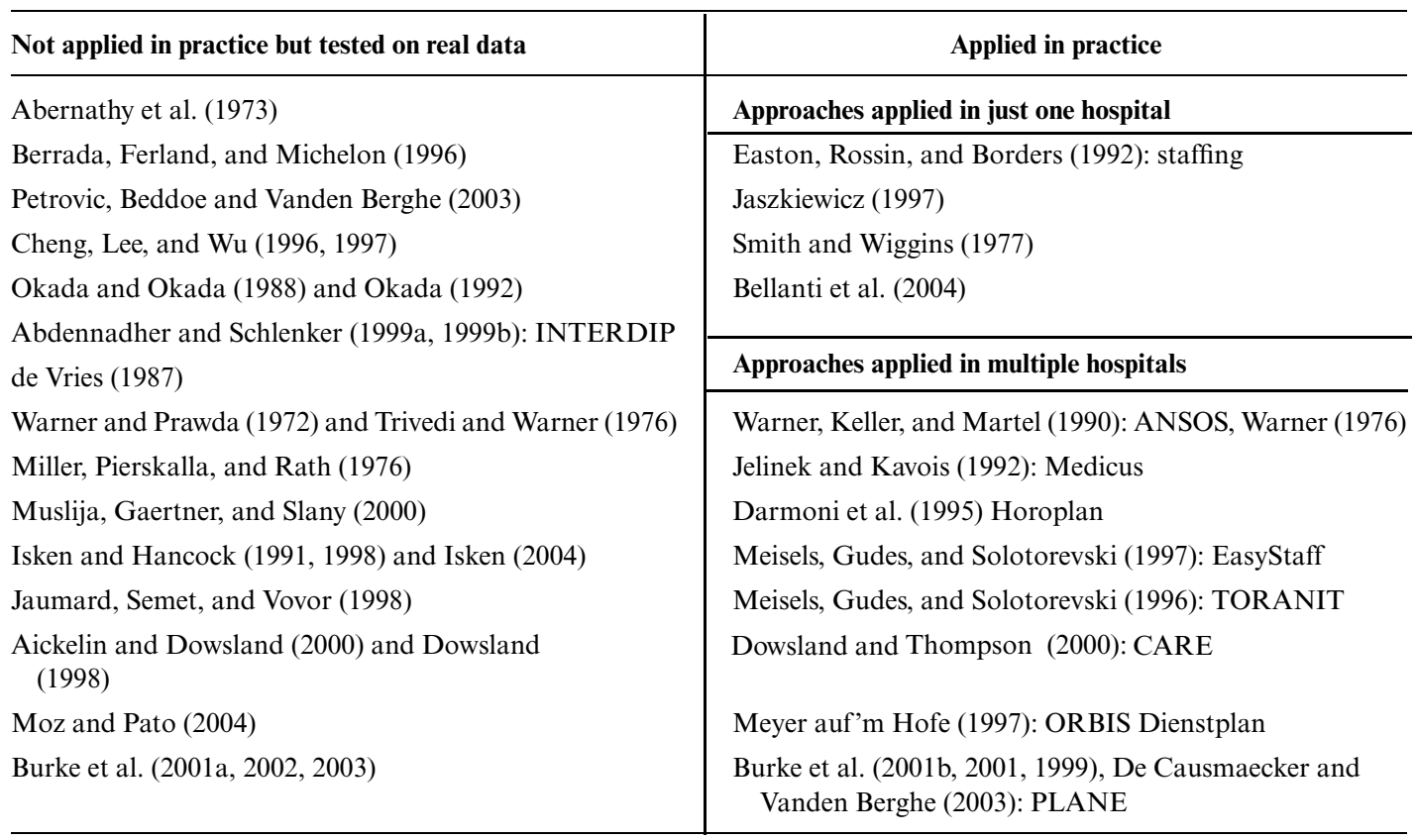

this table based upon the information available in the published papers. If this information needs updating then the authors should contact us. We intend to keep a regularly updated version of this table on the web. Authors and researchers with new information should contact us. The website is http://ingenieur.kahosl.be/vakgroep/it/nurse/applied_approaches.htm.

Although we argue above that there is still a gap between theory and practice in nurse scheduling research, it is clear that the field has come a long way since the early days. One of the two main goals of this paper is to present an analysis and discussion of the key methods and approaches to nurse scheduling that have appeared over the years and to outline the current state of the art in the field. Table 1 clearly demonstrates that modern hybridised artificial intelligence and operations research techniques which incorporate problem specific information form the basis of most successful real world implementations. Exact methods represented some of the early approaches to solving the problem but they cannot cope with the enormous search spaces that are represented by real problems (at least on their own). There is evidence to suggest that there is research scope in hybridising exact methods with heuristic approaches. Although it is the case that exact methods may be able to aid heuristics it is clear that some kind of (hybrid) heuristic method offers the only realistic way of tackling such difficult and challenging problems in the foreseeable future. However, heuristic methods alone cannot cope with the dynamic and uncertain nature of modern problems (see below). The current state of the art is represented by interactive approaches which incorporate problem specific methods and heuristics (that are derived from specific knowledge of the problem and the required constraints) with powerful modern metaheuristics, constraint based approaches and other search methods.

The second main motivating goal of this paper is to present some future directions for nurse scheduling research that are based on a clear analysis of past scientific achievements and on 
a clear appreciation of the demands of the environment in modern healthcare institutions. As already stated above, one obvious goal that modern nurse scheduling research has to tackle is to develop models and problem solving techniques that capture the needs and requirements of the real situation. As we have mentioned in the earlier discussion, many of the attempts to address nurse scheduling have tackled simplified problems. These simplified models may provide algorithmic insight (in a general sense) and they may provide benchmark problems to test new algorithms and developments. They serve a useful purpose within a general scientific framework. However, what we are arguing in this paper is that they do not directly advance our capability to solve real nurse scheduling problems in real hospitals. If this is our goal, then we must address the full range of requirements and demands that are presented by modern hospital workplaces.

This assertion leads to some challenging research issues which are constantly changing as emerging technologies impact upon the workplace. Here we list and briefly discuss some of the future research directions that we believe represent promising avenues for nurse scheduling research. Success in tackling some of these issues would make progress in closing the gap between nurse scheduling theory and practice. Such success would also underpin a new generation of more powerful decision support systems which better capture the needs of the hospital work place. Some of the important issues which need to be tackled and addressed are briefly discussed below. Ernst et al. (2004) outline some of these future research directions in a more general personnel scheduling context.

- Multi-criteria Reasoning: Nurse scheduling in hospital environments presents a range of objectives and requirements (Burke, De Causmaecker, and Vanden Berghe, 2004). Many of these objectives are conflicting. For example, it is easy to see how an objective that aims to maximise staff preferences may conflict with an objective that requires a certain number of staff to work a certain shift. Multi-objective reasoning has been investigated successfully for a range of scheduling problems (e.g. Burke, Bykov, and Petrovic, 2000; Lotfi and Cerveny, 1991; Paechter et al., 1998) and, indeed early steps to explore multi-objective reasoning have been made (Berrada, Ferland, and Michelon, 1996; Burke et al., 2002; Jaszkiewicz, 1997). It can be argued that because nurse scheduling is inherently multi-objective then nurse scheduling decision support technology should reflect this. It is clear that there is considerable scope for research in this area and it could be argued that multi-objective reasoning has a major role to play in future nurse scheduling research.

- Flexibility and Dynamic Reasoning: A key feature of real nurse scheduling problems is that the 'planned' personnel schedule usually has to be changed (often at very short notice) to deal with unforseen circumstances such as staff sickness and emergencies (Burke et al., 2001c; De Causmaecker and Vanden Berghe, 2003). As can be seen from our earlier discussion of the literature, very little work has been carried out on developing decision support technology that can address and deal with the uncertainty that is inherent in the real world. The question of how to develop such technology is very much an open question but it is one that the scientific community should address. Fuzzy reasoning has been investigated with some success (Meyer auf'm Hofe, 2001) and there is a growing body of literature which deals with fuzzy reasoning for other scheduling problems (e.g. Slowiński and Hapke, 2000). There is a certain amount of promise in investigating fuzzy methodologies as an attempt to address the dynamic nature of the problem in practice and as an attempt to deal with the inherent uncertainty that is a feature of the real world.

- Robustness: It follows from the previous point that the personnel schedule in hospital environments has to change to cope with unforseen events. We wish to avoid situations where (for 
example) just one person calling in sick causes a chain reaction of disruptions throughout the hospital because that person is the only scheduled person with a particular expertise (say). A more robust schedule would have had two (or more) people with that particular expertise scheduled to be at work at the same time. It is clear from the discussion in this article that robustness in nurse rostering has not played a major role in the scientific research literature. However, it does represent an important area in the uptake of nurse rostering research methods and it is important that the scientific community starts to address this issue with respect to real nurse rostering problems.

- Ease of Use: It follows from our earlier discussion, that many nurse scheduling research papers develop algorithmic approaches without any concern for the following question: If the developed algorithm were incorporated as the search 'engine' for a decision support system on a real hospital ward, how easy would the system be to use? As we have seen, academic research on nurse scheduling problems is often concerned with developing algorithms to solve various versions of the problem. The emphasis is on demonstrating that the developed algorithms are (in some sense) better than other algorithms. The usual definitions of better are that the algorithm produces lower penalty values on certain problems than other algorithms. Sometimes the amount of computational time required plays a role in the evaluation of nurse scheduling algorithms but it is quite rare for potential ease of use to play a role in these developments. Ease of use is, however, an absolutely crucial feature in the uptake of a decision support system. Many of the algorithmic methods that we have discussed in this paper require significant research expertise to employ (such as in setting the correct parameters). For example, it is unrealistic to expect a hospital administrator to alter cooling schedules for simulated annealing or the tabu tenure for tabu search or any of the other parameters that play a role in these and other metaheuristics. Of course, there are ways to address this issue such as 'hiding' such parameter selection within the interface by employing easily accessible terminology or by pre-setting the parameters. However, a significant research goal for the scientific community would be to investigate algorithmic methods for nurse scheduling that are less reliant upon parameters. There may well be far more scope for implementing a 'parameterless' algorithm in the real world than for implementing a conventionally better algorithm (i.e. one which generates lower penalties on benchmark problems) which requires significant parameter tuning. It is also desirable to develop algorithms that have parameters that hospital administrators can understand and use. One such parameter might be the computational time that an algorithm is allowed. The research challenge would be to develop a method that can be presented with a variable amount of computational time and which intelligently uses all the time it has been given to effectively explore the search space. It is easy to envisage certain scenarios where an administrator needs an instant solution (e.g. when someone has just called in sick) and other scenarios where the user would like the algorithm to spend a lot of time to find a very high quality schedule (e.g. generating next month's personnel schedule). Some work has been carried out in this area within the context of examination timetabling (Burke et al., 2004).

- Human/Computer Interaction: We know from the above discussion that scientific research into nurse scheduling problems has been primarily concerned with developing algorithms for various models of the problem. We have argued in this article that these models have often been too simple to directly apply to modern hospitals and we have also argued that the measures of evaluating algorithmic approaches do not consider some issues that are relevant to real world uptake (such as ease of use). The analysis of the current state of the art that is presented in this article shows us that it is also the case that little work has been carried 
out on algorithmic development for nurse scheduling that interfaces with human input to the scheduling process. However, if algorithms from the research community are going to be applied in real hospital situations then they have to interface with the administrators and nurses that will use them. This is a broad research direction which needs more consideration by researchers tackling nurse scheduling problems.

- Problem Decomposition: The idea of intelligently breaking up larger problems into smaller, easier to handle sub-problems and then dealing with each sub-problem in turn has been shown to work well in nurse rostering (e.g. Aickelin and Dowsland, 2000; De Causmaecker and Vanden Berghe, 2003) on other scheduling/timetabling problems (e.g. Burke and Newall, 1999; Carter, 1983). Of course, the major potential drawback with this type of approach is that it is possible to make allocations in earlier sub-problems which mean that later sub-problems cannot be solved. The key issue is to divide the larger problem into appropriate sub-problems in order to avoid this drawback and to develop appropriate mechanisms to attempt to avoid it as the allocations are made. A significant observation from the real world situation is that nurse scheduling problems can be very large and one way of dealing with large problems is to investigate decomposing them into smaller problems. Although some work has already been carried out in this area (see above), we think there is significant scope for further research.

- Exploitation of Problem Specific Information: One of the key conclusions that can be drawn from this article is that the full range of constraints and requirements that are generated by real hospital problems has not been addressed enough in the scientific literature on nurse scheduling. We strongly argue in this article that these constraints and requirements should be investigated by the scientific community and that methods/knowledge/heuristics that deal with such constraints and requirements should be fully integrated with approaches to solve nurse scheduling problems.

- Hybridisation: It is absolutely clear from the discussions in this article and from the successes in other scheduling and optimisation applications that no one technique or method is going to increase the uptake of nurse scheduling research methods on its own. Progress will be made by drawing on the strengths and capabilities of a range of methods, approaches and research advances. The successfully applied approaches in Table 1 are all hybrid methods (in one sense or another). The research directions that have been briefly highlighted in this article are not single directions that should be explored in isolation from each other. On the contrary, each of these themes should be explored in conjunction with each other and successes in one should feed into the others and vice versa.

- Inter-disciplinarity: It can be seen from the articles that have been reviewed and discussed in this paper that they represent a broad range of 'traditional' academic disciplines. Nurse scheduling research has drawn on expertise in many disciplines in the past and we contend that, in the future, this inter-disciplinary aspect should not only be continued but should be actively and significantly increased. In our view, an inter-disciplinary approach to future nurse rostering research is absolutely crucial. We argue that increased inter-disciplinary collaborations between the scientific community represents a significant prospect for future research success. It can be easily seen that the research themes that have been outlined above will require research expertise from the disciplines of operations research, artificial intelligence, healthcare administration, management, psychology and software engineering (among others). We believe that the fostering of inter-disciplinary collaborations is one of the most important tasks that the scientific community should carry out in order to make serious scientific advances in nurse rostering research and to increase the uptake of that research in the real world. 
It is important to note that the authors of this article completely recognise that the above (rather short) list does not represent all (or even close to all) the research directions that need exploring in nurse rostering research over the next few years. The list is simply an indication of just some of the directions that may lead to significant research advances in the area. It is also important to note that most of the above issues impact upon other scheduling problems but our arguments in this paper have been based exclusively upon the demands and needs of nurse rostering research. Of course (as we have already mentioned) all of the above cannot be tackled in isolation from each other. All of these future directions impact upon each other to a greater or lesser extent. In particular, one absolutely critical issue that impacts upon all of these research directions is that they should be developed for and evaluated upon real world data. We believe that it is extremely important to start building up easily accessible benchmark problems from practice. It is also necessary that these problems include the issues that really are important to hospital administrators. We will start to collect such data and we would like to ask researchers in the community to help to contribute to this nurse scheduling problem archive. The data sets (together with instructions on how to contribute data sets) are available at http://ingenieur.kahosl.be/vakgroep/it/nurse/archive.htm.

In summary, we need to pay more attention, as a scientific community, to the issues that are important to modern hospital administrators in order to increase the uptake of nurse rostering research in the real world. Modern environments represent far more difficult problems than those that are tackled by many of the research papers in the literature. In particular, we need to be less rigid when we are evaluating algorithms. Of course, it is important to develop better penalty results on benchmarks and to work towards better computational time. However, features that are less easy to measure also play a role in real world uptake. These include levels of flexibility, ease of use, robustness, capability of handling uncertainty and human/machine interaction. It is very clear that significant advances in nurse rostering research have been achieved in the last 40 years but there are many more advances to be made and some very difficult research challenges to tackle. We look forward to seeing how they are addressed in the next 40 years!

\section{ACKNOWLEDGMENTS}

We would like to thank the anonymous referees for their detailed and helpful comments.

\section{APPENDIX A: PHD DISSERTATIONS}

A list of $\mathrm{PhD}$ dissertations on the topic of hospital scheduling is summarised below:

- D.M. Warner: A Two Phase Model for Scheduling Nursing Personnel in a Hospital, Tulane University, New Orleans, LA (unpublished), 1971.

- D. Schneider: A Systems Analysis of Optimal Manpower Utilization in Health Maintenance Organizations, University of Florida, Gainesville, Florida, 1973.

- V.M. Trivedi: Optimum Allocation of Float Nurses Using Head Nurses' Perspectives, University of Michigan, Ann Arbor, Michigan (unpublished), 1974.

- G. de Vries: Evenwicht in zorgvraag en zorgaanbod: besturing van de afstemming op verpleegkundigen (Equilibrium in Supply and Demand in Healthcare: Attunement on the Nursing Units), Eindhoven University of Technology, 1984. 
- M.V. Tobon Perez: An Integrated Methodology to Solve Staffing, Scheduling and Budgetting Problems in a Nursing Department, University of Pittsburgh, 1984.

- D. Lukman: A Hierarchical Approach in Schedule Formulation and Maintenance under Uncertainty, University of Pittsburgh, 1986.

In the developed rule based decision support system there is no possibility for changing or adding rules, and the number of required personnel is not calculated. The system allows for qualitative considerations without quantitative values.

- I. Ozkarahan: A Flexible Nurse Scheduling Support System, Arizona State University, 1987.

A goal programming formulation, including both the determination of possible schedules and the assignment of individual nurses to these schedules is presented in this work. Ozkarahan realises that her formulation requires a zero-one integer program which is much larger than anything available at that time. The work is a part of a large decision support system which can incorporate artificial intelligence techniques in the nurse scheduling process.

- J.M.H. Vissers: Patient flow based allocation of hospital resources, Eindhoven University of Technology, 1994.

This research focuses on the analysis, design and control of operational health care processes and systems. Special interest areas are the development of the process concept and the allocation of shared resources within a hospital setting and beyond. The personnel scheduling part of this works belongs to the staffing domain.

- M.W. Isken: Personnel Scheduling Models for Hospital Ancillary Units, University of Michigan, 1995.

Isken developed several models and techniques for tactical scheduling analysis (denoted as 'staffing' in the review). The models consider all the specialised units in hospitals (laboratories, pharmacy) that are not regular wards. The results of Isken's models are the input for operational personnel scheduling.

- J.H. Oldenkamp: Quality in Fives: On the Analysis, Operationalization and Application of Nursing Schedule Quality, Rijksuniversiteit Groningen, 1996.

This thesis describes a study of the support of scheduling nurses, in which it focusses on the consequences of nursing schedules on the performance of the nursing unit. Three parts are distinguished in this performance: the effectiveness in providing nursing care, the efficiency of a nursing unit and, the influence of a nursing schedule on the nursing unit's performance.

- U. Aickelin: Genetic Algorithms for Multiple-Choice Optimisation Problems, European Business Management School University of Swansea, 1999.

Nurse rostering is one of the multiple choice problems addressed by Aickelin's work. The corresponding part of that thesis is called 'A Direct Genetic Algorithm Approach for Nurse Scheduling'. The main aim is to balance feasibility and solution cost or quality within a genetic algorithm framework.

- H. Meyer auf'm Hofe: Kombinatorische Optimiering mit ConstraintverfahrenProblemlösung ohne anwendungsspezifische Suchstrategien, University of Kaiserslautern, 2000.

This work builds on the development of a constraint library for a commercial personnel planning system. Soft constraints represent different kinds of restrictions on personal schedules, going from rather strict general conditions to flexible personal requests and costs. Search algorithms for the combinatorial problems make use of special propagation procedures from the constraint library. 
- A. Ikegami: Nurse Scheduling in Japan -Modeling and Solution, Seikei University, Tokyo, 2001 (in Japanese).

- G. Vanden Berghe: An Advanced Model and Novel Metaheuristic Solution Methods to Personnel Scheduling in Healthcare, University of Gent, 2002.

\section{APPENDIX B: A CLASSIFICATION OF PAPERS BY THE CONSTRAINTS AND PARAMETERS THAT THEY CONSIDER}

Tables 2 to 20 help to place each tackled problem within the context of the group of problems studied in the literature. They present a systematic overview of some relevant parameters and objectives collected from a range of publications. The authors are aware that the information in the tables may be

Table 2. Coverage and time related constraints are considered as hard and/or soft constraints

\begin{tabular}{|c|c|c|}
\hline & Hard constraints & Soft constraints \\
\hline \multirow[t]{8}{*}{ Coverage } & $\begin{array}{l}\text { Burke et al. (2001a, 2001b, 2003), Burke, } \\
\text { De Causmaecker, and Vanden Berghe (1999), } \\
\text { De Causmaecker and Vanden Berghe (2003): } \\
\text { allow relaxation of coverage constraints }\end{array}$ & Meyer auf'm Hofe $(1997,2001)$ \\
\hline & Kawanaka et al. (2001) & Chen and Yeung (1993) \\
\hline & $\begin{array}{l}\text { Warner and Prawda (1972): minimum coverage is } \\
\text { obligatory }\end{array}$ & $\begin{array}{l}\text { Warner (1976): minimum coverage can be } \\
\text { violated on predefined days }\end{array}$ \\
\hline & Meisels, Gudes, and Solotorevski (1996) & Warner, Keller, and Martel (1990) \\
\hline & $\begin{array}{l}\text { Aickelin and Dowsland (2000), Aickelin and } \\
\text { White (2004), Dowsland (1998), Dowsland and } \\
\text { Thompson (2000) }\end{array}$ & Okada (1992), Okada and Okada (1988) \\
\hline & Schaerf and Meisels (1999) & Miller, Pierskalla, and Rath (1976) \\
\hline & Moz and Pato (2004) & Ikegami and Niwa (2003) \\
\hline & $\begin{array}{l}\mathrm{Li} \text {, Lim, and Rodrigues (2003): some of the } \\
\text { coverage constraints are hard }\end{array}$ & \\
\hline \multirow[t]{9}{*}{$\begin{array}{l}\text { Time related } \\
\text { constraints }\end{array}$} & Berrada, Ferland, and Michelon (1996) & $\begin{array}{l}\text { Warner (1976) and Warner, Keller, and Martel } \\
\text { (1990) }\end{array}$ \\
\hline & $\begin{array}{l}\text { Miller, Pierskalla, and Rath (1976): feasibility set } \\
\text { ( } 3 \text { constraints) }\end{array}$ & $\begin{array}{l}\text { Miller, Pierskalla, and Rath (1976): non-binding } \\
\text { constraints }\end{array}$ \\
\hline & Bellanti et al. (2004) & Meisels, Gudes, and Solotorevski (1996) \\
\hline & & $\begin{array}{l}\text { Burke et al. (2001a, 2001b, 2001c), Burke, } \\
\text { De Causmaecker, and Vanden Berghe (1999), } \\
\text { De Causmaecker and Vanden Berghe (2003) }\end{array}$ \\
\hline & & Meyer auf'm Hofe $(1997,2001)$ \\
\hline & & Ikegami and Niwa (2003) \\
\hline & & $\begin{array}{l}\text { Aickelin and Dowsland (2000), Aickelin and } \\
\text { White (2004), Dowsland (1998), Dowsland and } \\
\text { Thompson (2000) }\end{array}$ \\
\hline & & Moz and Pato (2004) \\
\hline & & Li, Lim, and Rodrigues (2003) \\
\hline
\end{tabular}


Table 3. A summary of which approaches, Optimising and Heuristic, tackle which objectives

\begin{tabular}{|c|c|c|}
\hline Objectives & Optimising & Heuristic \\
\hline $\begin{array}{l}\text { Minimise violations of time } \\
\text { related constraints }\end{array}$ & $\begin{array}{l}\text { Warner (1976): schedules constructed } \\
\text { with predefined patterns, the objective } \\
\text { is to minimise } \sum_{\text {people }} \text { ('aversion' for } \\
\text { the pattern) } \\
\text { Warner, Keller, and Martel (1990) }\end{array}$ & $\begin{array}{l}\text { Burke et al. (2001b), minimise } \sum_{\text {people }} \\
\text { (violations on soft constraints), see also } \\
\text { Burke et al. (2001a, 2003), Burke, } \\
\text { De Causmaecker, and Vanden Berghe, } \\
\text { 1999, De Causmaecker and Vanden } \\
\text { Berghe (2003) } \\
\text { Arthur and Ravindran (1981): minimise } \\
\text { staff dissatisfaction by minimising the } \\
\text { number of staff with ungranted requests } \\
\text { Aickelin and Dowsland (2000), Aickelin } \\
\text { and White (2004), Dowsland (1998), } \\
\text { Dowsland and Thompson (2000) }\end{array}$ \\
\hline $\begin{array}{l}\text { Minimise violations of coverage } \\
\text { constraints }\end{array}$ & $\begin{array}{l}\text { Miller, Pierskalla, and Rath (1976): nearly } \\
\text { optimal solution generated with a } \\
\text { mathematical algorithm } \\
\text { Moz and Pato (2004) }\end{array}$ & $\begin{array}{l}\text { Okada (1992), Okada and Okada (1988) } \\
\text { Ikegami and Niwa (2003) } \\
\text { Bellanti et al. (2004) }\end{array}$ \\
\hline Minimise number of employees & Alfares (2000) & $\begin{array}{l}\text { Arthur and Ravindran (1981) } \\
\text { Easton and Mansour (1993) }\end{array}$ \\
\hline Minimise personnel cost & $\begin{array}{l}\text { Jaumard, Semet and Vovor (1998): satisfy } \\
\text { the coverage while minimising the } \\
\text { salary costs and maximising the } \\
\text { employee preferences and team balance } \\
\text { Tanomaru (1995) } \\
\text { Isken (2004) }\end{array}$ & $\begin{array}{l}\text { Meyer auf'm Hofe (1997) takes personnel } \\
\text { costs into account in addition to the } \\
\text { cost for expenditure of work }\end{array}$ \\
\hline $\begin{array}{l}\text { Minimise non-negative 'under' } \\
\text { coverage }\end{array}$ & $\begin{array}{l}\text { Warner and Prawda (1972): the cost for } \\
\text { 'nursing care shortage' is minimised }\end{array}$ & \\
\hline $\begin{array}{l}\text { Uniform distribution of } \\
\text { shortages and surpluses over } \\
\text { weekdays }\end{array}$ & Berrada, Ferland, and Michelon (1996) & \\
\hline $\begin{array}{l}\text { Minimise deviation between } \\
\text { scheduled nurses and demand }\end{array}$ & & $\begin{array}{l}\text { Ozkarahan (1991): minimise nurse } \\
\text { shortages and surpluses } \\
\text { Arthur and Ravindran (1981) }\end{array}$ \\
\hline $\begin{array}{l}\text { Minimise deviation between } \\
\text { scheduled people and the } \\
\text { total work capacity from the } \\
\text { work regulations }\end{array}$ & Ozkarahan and Bailey (1988) & \\
\hline
\end{tabular}

incomplete and we ask other researchers to contact us with suggested changes. We will keep an updated archive of these tables at http://ingenieur.kahosl.be/vakgroep/it/nurse/classification.htm.

In the main body of the paper we were particularly concerned with the real world nature of the problems tackled: the flexibility of defining shift types, work regulations, skill categories, stochastically varying workload and the applicability in practice. 
Table 4. Flexibility of setting and defining problem parameters

\begin{tabular}{|c|c|c|}
\hline Parameters & Constraints & Costs and weights \\
\hline \multirow[t]{2}{*}{$\begin{array}{l}\text { Fixed: predefined parameter } \\
\text { values and constraints }\end{array}$} & $\begin{array}{l}\text { Aickelin and Dowsland (2000), Aickelin } \\
\text { and White (2004), Dowsland (1998) }\end{array}$ & Dowsland and Thompson (2000) \\
\hline & Warner (1976) & $\begin{array}{l}\text { Berrada, Ferland, and Michelon (1996): } \\
\text { weights are fixed }\end{array}$ \\
\hline \multirow{6}{*}{$\begin{array}{l}\text { Adaptable: users can set the } \\
\text { values of the problem } \\
\text { parameters }\end{array}$} & Musa and Saxena (1984) & Musa and Saxena (1984) \\
\hline & $\begin{array}{l}\text { Warner and Prawda (1972): a few } \\
\text { organisational constraints }\end{array}$ & $\begin{array}{l}\text { Warner (1976): personal and unit wide } \\
\text { 'aversion' for patterns }\end{array}$ \\
\hline & Miller, Pierskalla, and Rath (1976) & $\begin{array}{l}\text { Miller, Pierskalla, and Rath (1976): } \\
\text { personal 'aversion' for nonbinding } \\
\text { constraints }\end{array}$ \\
\hline & Ikegami and Niwa (2003) & \\
\hline & Bellanti et al. (2004) & \\
\hline & Okada (1992) & \\
\hline \multirow[t]{4}{*}{$\begin{array}{l}\text { User definable: the users } \\
\text { define the problem } \\
\text { parameters }\end{array}$} & $\begin{array}{l}\text { Burke et al. (2001a, 2001b, 2002, 2003) and } \\
\text { Burke, De Causmaecker, and Vanden } \\
\text { Berghe (1999) and De Causmaecker and } \\
\text { Vanden Berghe (2003) }\end{array}$ & $\begin{array}{l}\text { Burke et al. (2001a, 2001b, 2003) and } \\
\text { Burke, De Causmaecker, and Vanden } \\
\text { Berghe (1999) and De Causmaecker } \\
\text { and Vanden Berghe (2003) }\end{array}$ \\
\hline & $\begin{array}{l}\text { Weil et al. (1995): generic model can cope } \\
\text { with different legal regulations }\end{array}$ & Weights in Burke et al. (2002) \\
\hline & Meyer auf’m Hofe (2001) & Meyer auf'm Hofe (2001) \\
\hline & Meisels, Gudes, and Solotorevski (1996) & Meisels, Gudes, and Solotorevski (1996) \\
\hline
\end{tabular}

When only considering the short-term rostering problem, two main goals are distinguished: coverage and time related constraints for personnel. It is necessary for the hospital management to provide enough assigned personnel at any time of the planning period, at the expense of violations on time related constraints. Table 2 groups papers according to the way they tackle coverage and time related constraints. Those who set coverage as a hard constraint do not allow any violations of coverage constraints at all. The upper left part of the table groups such papers. In other approaches, coverage constraints are preferably satisfied but they are treated as soft constraints (upper right part of Table 2). For very flexible rostering of real world problems, time related constraints are rarely hard. However, two examples of approaches that do not accept violations of such constraints are given in the lower left part of the table. Most models attempt to minimise violations on time related constraints that are treated as soft constraints. These are grouped in the lower right part of Table 2. De Causmaecker and Vanden Berghe (2003) present a set of relaxation procedures for the coverage constraints.

The approaches in which personnel requirements are not hard allow management level decisions in the short-term planning. Those that have hard time related constraints all have fewer and less strict constraint types. 
Table 5. Summary of cyclical and non-cyclical approaches

\begin{tabular}{|c|c|c|}
\hline Cyclical & Semi-cyclical & Non-cyclical \\
\hline $\begin{array}{l}\text { Chan and Weil (2001): but } \\
\text { flexible with respect to } \\
\text { annual leave and } \\
\text { unexpected events }\end{array}$ & $\begin{array}{l}\text { The model in Burke et al. (2001b) provides } \\
\text { the possibility to define cyclical patterns } \\
\text { that can be superimposed on } \\
\text { non-cyclical schedules }\end{array}$ & $\begin{array}{l}\text { Burke et al. (2001a, 2001b, 2002), Burke, } \\
\text { De Causmaecker, and Vanden Berghe } \\
\text { (1999), De Causmaecker and Vanden } \\
\text { Berghe (2003) }\end{array}$ \\
\hline $\begin{array}{l}\text { Muslija, Gaertner, and } \\
\text { Slany (2000) }\end{array}$ & $\begin{array}{l}\text { Warner (1976): manual preprocessing of the } \\
\text { number of people who rotate day and night } \\
\text { weeks }\end{array}$ & $\begin{array}{l}\text { Aickelin and Dowsland (2000), Aickelin } \\
\text { and White (2004), Dowsland (1998) } \\
\text { (however, night shifts cannot be } \\
\text { scheduled together with morning/late } \\
\text { shifts during the same week), Dowsland } \\
\text { and Thompson (2000) }\end{array}$ \\
\hline Alfares (2000) & $\begin{array}{l}\text { Smith (1976): not all the personnel } \\
\text { members have a rotating schedule }\end{array}$ & Okada (1992), Okada and Okada (1988) \\
\hline Burns (1978) & Chan and Weil (2001) & Miller, Pierskalla, and Rath (1976) \\
\hline Burns and Koop (1987) & & Meyer auf'm Hofe (2001) \\
\hline \multirow[t]{3}{*}{ Baker (1974) } & & Kawanaka et al. (2001) \\
\hline & & Schaerf and Meisels (1999) \\
\hline & & Ikegami and Niwa (2003) \\
\hline
\end{tabular}

The objectives differ from approach to approach, which is clear from the straightforward categories in Table 2. In Table 3, a list of possible goals is presented in two different categories: the optimising and the heuristic approaches. Examples of objectives are:

- Minimise 'under'coverage. The coverage constraints are soft constraints.

- Minimise deviation between scheduled nurses and demand. In this approach both over- and undercoverage are allowed but not wanted. The deviation from the coverage constraints has to be minimised.

- Minimise number of employees. The number of employees is not fixed and this objective belongs more to the staffing domain.

- Minimise personnel cost. Labour costs can be reduced by minimising the amount of overtime but also by minimising the number of expensive staff.

- Uniform distribution of shortages and surpluses over weekdays. Violations of the coverage constraints have to be evenly spread over the days of the planning period.

- Minimise deviation between scheduled people and the total work capacity for the work regulations. The purpose of this objective is to satisfy the contractual requirements better and thus reduce over- and undertime.

Examples with fixed constraints and parameters are quite rare and they are very often theoretical implementations of one single problem. Most models allow the user to adapt some predefined constraints and penalty values to their own needs (Table 4). The column entitled "Constraints" denotes how flexible the models are towards defining constraints. The approaches with fixed constraints are placed higher up in the column. The second level in the column shows contributions in which constraint parameters can be set by the users. The most flexible ones are at the bottom. They are models in which users can define the problem parameters themselves. 
Table 6. Approaches for tackling coverage constraints

\begin{tabular}{|c|c|c|c|c|}
\hline \multicolumn{2}{|c|}{ Understaffing } & \multicolumn{2}{|c|}{ Overstaffing } & \multirow[t]{2}{*}{ More Options } \\
\hline Allowed & Not allowed & Allowed & Not allowed & \\
\hline $\begin{array}{l}\text { Miller, Pierskalla, and Rath } \\
\text { (1976) }\end{array}$ & $\begin{array}{l}\text { De Causmaecker and } \\
\text { Vanden Berghe } \\
\text { (2003): unless certain } \\
\text { circumstances occur, } \\
\text { consistency check }\end{array}$ & $\begin{array}{l}\text { Miller, Pierskalla, and Rath } \\
\text { (1976) }\end{array}$ & $\begin{array}{l}\text { De Causmaecker and Vanden } \\
\text { Berghe (2003): unless certain } \\
\text { circumstances occur (e.g. } \\
\text { avoiding undertime) }\end{array}$ & $\begin{array}{l}\text { De Causmaecker and Vanden } \\
\text { Berghe (2002): consistency } \\
\text { check, the range between } \\
\text { minimum and preferred coverage } \\
\text { is flexible }\end{array}$ \\
\hline $\begin{array}{l}\text { Warner, Keller, and Martel } \\
\quad(1990)\end{array}$ & $\begin{array}{l}\text { Burke et al. } \\
\text { (2001a, 2001b, 2003), } \\
\text { Burke, } \\
\text { De Causmaecker, and } \\
\text { Vanden Berghe (1999) }\end{array}$ & $\begin{array}{l}\text { Warner, Keller, and Martel } \\
\quad(1990)\end{array}$ & $\begin{array}{l}\text { Burke et al. (2001a, 2001b, 2003), } \\
\text { Burke, De Causmaecker, and } \\
\text { Vanden Berghe (1999) }\end{array}$ & \\
\hline Warner (1976) & $\begin{array}{l}\text { Warner and Prawda } \\
\text { (1972) }\end{array}$ & Warner and Prawda (1972) & & \\
\hline Ozkarahan (1991) & Kawanaka et al. (2001) & Ozkarahan (1991) & & \\
\hline Isken and Hancock (1991) & $\begin{array}{l}\text { Meyer auf'm Hofe } \\
\text { (2001) }\end{array}$ & Isken and Hancock (1991) & & $\begin{array}{l}\text { Meyer auf'm Hofe (2001) defines } \\
\text { minimum and standard staffing } \\
\text { levels which are treated as fuzzy } \\
\text { constraints, there is a } \\
\text { considerably larger penalty for } \\
\text { understaffing than for } \\
\text { overstaffing }\end{array}$ \\
\hline \multirow[t]{4}{*}{ Bellanti et al. (2004) } & $\begin{array}{l}\text { Jan, Yamamoto, and } \\
\text { Ohuchi (2000) }\end{array}$ & $\begin{array}{l}\text { Jan, Yamamoto, and } \\
\text { Ohuchi (2000) only for } \\
\text { day shifts }\end{array}$ & & \\
\hline & $\begin{array}{l}\text { Schaerf and Meisels } \\
\text { (1999) }\end{array}$ & $\begin{array}{l}\text { Okada (1992), Okada and } \\
\text { Okada (1988) }\end{array}$ & Schaerf and Meisels (1999) & \\
\hline & $\begin{array}{l}\text { Valouxis and Housos } \\
\text { (2000) }\end{array}$ & $\begin{array}{l}\text { Valouxis and Housos } \\
\text { (2000) }\end{array}$ & & \\
\hline & $\begin{array}{l}\text { Aickelin and Dowsland } \\
\text { (2000), Aickelin and } \\
\text { White (2004), } \\
\text { Dowsland (1998) and } \\
\text { Dowsland and } \\
\text { Thompson (2000) }\end{array}$ & & $\begin{array}{l}\text { Aickelin and Dowsland (2000), } \\
\text { Aickelin and White (2004), } \\
\text { Dowsland (1998), Dowsland and } \\
\text { Thompson (2000): overstaffing is } \\
\text { not allowed for night shifts }\end{array}$ & \\
\hline
\end{tabular}


Table 7. Number of skill categories and substitutability

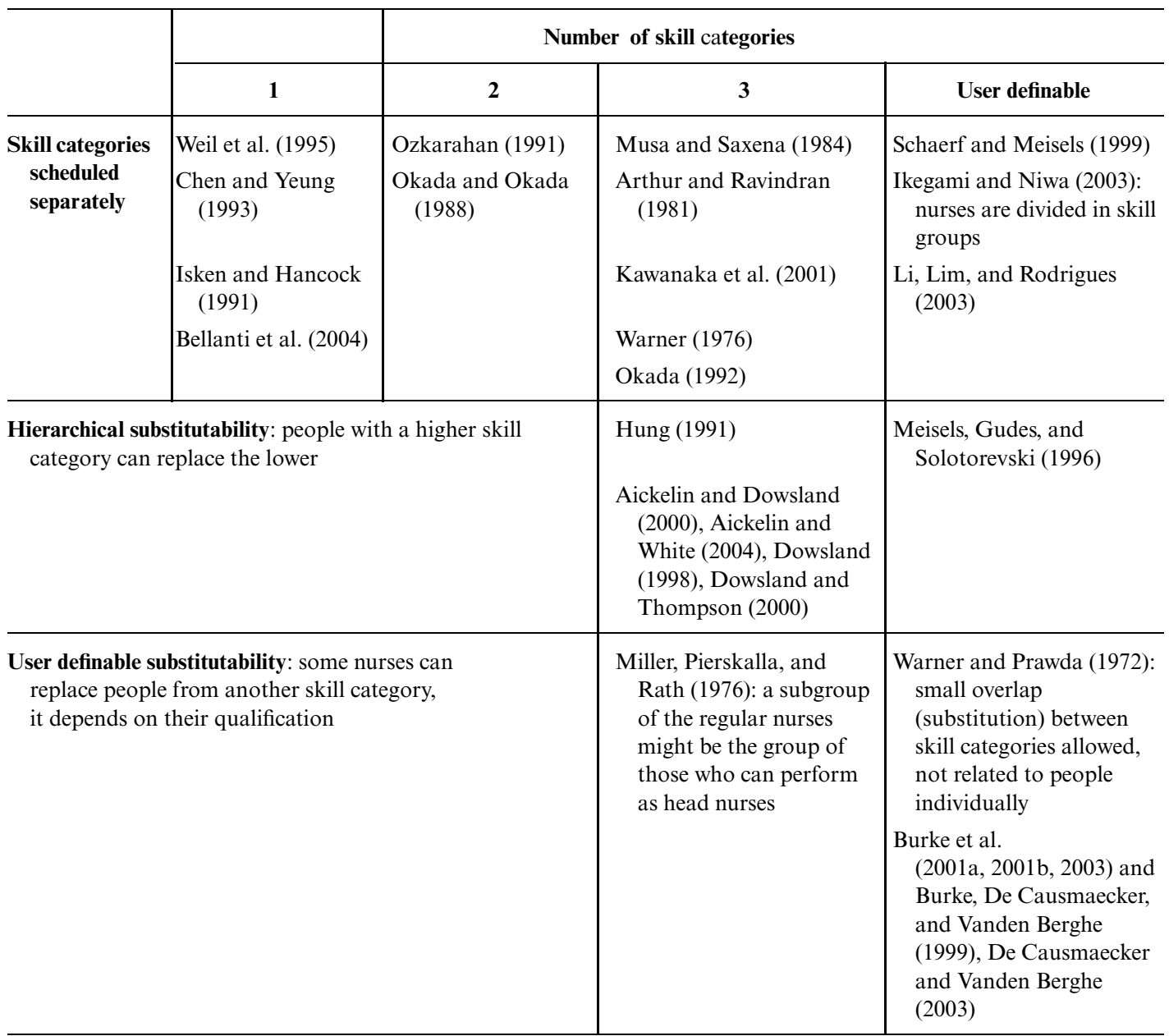

We have collected information about modifiable costs and weights in the right hand column. Again, the papers are presented in order of increasing complexity towards the bottom of the table.

Flexible software systems, which are extendible with new constraints and which have modifiable costs and weights, are, of course much more difficult to build.

Generally, the design of cyclical schedules requires more than short-term rostering decisions only (see also Section 2.4). However, once the requirements are set, cyclical schedules are much easier to generate than others because the search space is considerably smaller. Table 5 divides approaches into cyclical, semi-cyclical, and non-cyclical methods. The left hand column enumerates some of the pure cyclical methods. The models that are grouped in the middle column describe mixed approaches. Burke et al. (2001b), for example, developed an intrinsically non-cyclical model but it provides means for setting constraints that superimpose cyclical patterns upon certain personal schedules. The model thus includes certain cyclical aspects for non-cyclical rosters. Warner (1976) proposes a different solution in which personal rosters either obey cyclical or non-cyclical rules. 
Table 8. Flexibility in setting and defining work regulations

\begin{tabular}{|c|c|}
\hline $\begin{array}{l}\text { Identical work } \\
\text { regulations for } \\
\text { all people }\end{array}$ & $\begin{array}{l}\text { Miller, Pierskalla, and Rath (1976): full time nurses only } \\
\text { Arthur and Ravindran (1981): full time nurses only } \\
\text { Weil et al. (1995): full time nurses only } \\
\text { Warner and Prawda (1972): no distinction between people } \\
\text { Chen and Yeung (1993) } \\
\text { Bellanti et al. (2004) }\end{array}$ \\
\hline $\begin{array}{l}\text { Mixed workforce: Full time and } \\
\text { half time nurses }\end{array}$ & $\begin{array}{l}\text { Ozkarahan and Bailey (1988): different work regulations } \\
\text { Musa and Saxena (1984): various part time options are possible } \\
\text { Dowsland and Thompson (2000) } \\
\text { Isken (2004) }\end{array}$ \\
\hline User definable work regulations & $\begin{array}{l}\text { Burke et al. (2001a, 2001b, 2003) and Burke, De Causmaecker, and Vanden } \\
\text { Berghe (1999) and De Causmaecker and Vanden Berghe (2003) } \\
\text { Meyer auf'm Hofe (1997, 2001) } \\
\text { Moz and Pato (2004): individual labour contracts } \\
\text { Chiarandini, Schaerf, and Tiozzo (2000) } \\
\text { Schaerf and Meisels (1999) } \\
\text { Warner (1976): people can have different 'contracted workloads' }\end{array}$ \\
\hline $\begin{array}{l}\text { Float nurses: Nurses from different } \\
\text { wards can solve personnel } \\
\text { shortage }\end{array}$ & $\begin{array}{l}\text { Warner and Prawda (1972): generally, nurses are assigned wards can solve } \\
\text { personnel shortage to a unit and do not move around at zero cost; a few } \\
\text { 'float' nurses do move around } \\
\text { De Causmaecker and Vanden Berghe (2003): it is possible to let people work } \\
\text { in more than one ward } \\
\text { Meyer auf'm Hofe (1997, 2001) constrains the expenditure of work } \\
\text { Warner, Keller, and Martel (1990): a special 'float pool' of personnel is } \\
\text { scheduled to facilitate last-minute changes } \\
\text { Trivedi and Warner (1976) }\end{array}$ \\
\hline
\end{tabular}

The last column groups models that are non-cyclical. They either allow all the possible variations of schedules and penalise the bad ones, or they select schedules from a limited set of desired shift sequences.

Many researchers are aware of the necessity of small violations of the coverage constraints when it comes to scheduling in practice (see Table 6), and penalise them in a cost function. The approaches that are grouped in the first column (where understaffing is allowed) and in the third one (overstaffing is allowed), take coverage as a goal to be reached. The contribution of De Causmaecker and Vanden Berghe (2003) is different. The coverage constraints are expected to be satisfied. If they are not carefully defined by the users, a consistency check will indicate infeasibilities. The model in De Causmaecker and Vanden Berghe (2003) provides several planning options to find the best coverage in every situation. The last column of the table presents some of the more flexible models with respect to coverage which best reflect the way coverage is often treated in real hospital environments. 
Table 9. Different definitions of coverage constraints

\begin{tabular}{|c|c|c|c|c|}
\hline & Days & Shifts & Hours & Minimum-preferred \\
\hline Constant & & $\begin{array}{l}\text { Jan, Yamamoto, and } \\
\text { Ohuchi (2000) }\end{array}$ & & \\
\hline Weekdays-weekends & & Kawanaka et al. (2001) & & \\
\hline \multirow{5}{*}{$\begin{array}{l}\text { Fluctuating: the } \\
\text { coverage } \\
\text { constraints vary } \\
\text { over the planning } \\
\text { period }\end{array}$} & $\begin{array}{l}\text { Miller, Pierskalla, } \\
\text { and Rath (1976) }\end{array}$ & $\begin{array}{l}\text { Warner (1976), Warner, } \\
\text { Keller, and Martel (1990) }\end{array}$ & $\begin{array}{l}\text { Miller, Pierskalla, } \\
\text { and Rath (1976) }\end{array}$ & $\begin{array}{l}\text { De Causmaecker and } \\
\text { Vanden Berghe (2003) }\end{array}$ \\
\hline & Alfares (2000) & $\begin{array}{l}\text { Burke et al. (2001a) and } \\
\text { Burke, De Causmaecker, } \\
\text { and Vanden Berghe } \\
\text { (1999) }\end{array}$ & $\begin{array}{l}\text { Burke et al. } \\
\quad(2001 \mathrm{c})\end{array}$ & $\begin{array}{l}\text { Burke et al. (2001a, } \\
\text { 2001c) and Burke, } \\
\text { De Causmaecker, and } \\
\text { Vanden Berghe (1999) }\end{array}$ \\
\hline & \multirow[t]{3}{*}{$\begin{array}{l}\text { Meyer auf'm Hofe } \\
(1997,2001)\end{array}$} & $\begin{array}{l}\text { Warner and Prawda (1972) } \\
\text { (4 days ahead) }\end{array}$ & $\begin{array}{l}\text { Meyer auf'm Hofe } \\
(1997,2001)\end{array}$ & $\begin{array}{l}\text { Warner and Prawda } \\
\text { (1972) }\end{array}$ \\
\hline & & $\begin{array}{l}\text { Aickelin and Dowsland } \\
\text { (2000), Aickelin and } \\
\text { White (2004), Dowsland } \\
\text { (1998), Dowsland and } \\
\text { Thompson (2000) }\end{array}$ & Isken (2004) & $\begin{array}{l}\text { Ikegami and Niwa } \\
\text { (2003): lower and } \\
\text { upper bound }\end{array}$ \\
\hline & & Bellanti et al. (2004) & & \\
\hline
\end{tabular}

As mentioned at some length in the main body of the paper, we have noted that there is a large gap between solving real problems and solving simplified ones. Many authors restrict the applicability of their models to some simplified examples of nurse rostering, with, for example, three different shifts, short planning horizons, a limited number of possible patterns for personnel members with an identical work regulation. In Tables 7 to 12, we have grouped specific dimensional units in order to identify the difficulty of the problems addressed.

We say that skill categories are hierarchically substitutable when people with higher skill categories can undertake jobs which are normally carried out by lower skilled people. In other situations, people from different skill categories can be substituted in a user defined way. The latter approach better reflects the situation in hospitals. It is often the case that among a group of people belonging to the same skill category, some will be more experienced or have better management skills and so will be more suitable to temporarily replace (say, for example) the head of their department.

In Table 7, we have grouped the publications according to the number of skill categories that the models can handle (columns), and to the way substitutability is organised. The leftmost columns contain the simpler models, whereas the columns on the right include models that are more suitable for practical applications. The top-down evolution in the tables also goes from simpler towards more complex models.

In simplified research examples, nurse rostering problems can be defined with equal constraints for all the personnel members. The assignment of schedules to people is in that case very straightforward. More realistic examples take part time contracts into account and provide flexibility to define personal work agreements. We have presented a classification (Table 8) of contributions according to the way they handle work regulations or contracts for different personnel members. The upper part of the table shows which approaches treat all the nurses equally with respect to 
Table 10. Flexibility of defining shift types

\begin{tabular}{|c|c|c|}
\hline & Strictly distinct & Overlapping allowed \\
\hline $\begin{array}{l}\text { One single shift or no shifts } \\
\text { defined: days }\end{array}$ & $\begin{array}{l}\text { Miller, Pierskalla, and Rath (1976) } \\
\text { Musa and Saxena (1984) } \\
\text { Narasimhan (1996) }\end{array}$ & \\
\hline $\begin{array}{l}\text { Three different shifts: usually } \\
\text { referred to as Morning, Late, } \\
\text { and Night shift }\end{array}$ & $\begin{array}{l}\text { Warner (1976) } \\
\text { Trivedi and Warner (1976) } \\
\text { Aickelin and Dowsland (2000), Aickelin } \\
\text { and White (2004), Dowsland (1998): the } \\
\text { night shifts are scheduled separately to a } \\
\text { certain extent and thus the complexity is } \\
\text { reduced to a 2-shift problem, Dowsland } \\
\text { and Thompson (2000) } \\
\text { Warner and Prawda (1972): } 3 \text { 8-hour shifts } \\
\text { per day } \\
\text { Berrada, Ferland, and Michelon (1996): } \\
\text { there is no rotation: the problem can be } \\
\text { split into } 3 \text { singleshift problems } \\
\text { Bellanti et al. (2004) } \\
\text { Moz and Pato (2004) } \\
\text { Jan, Yamamoto, and Ohuchi (2000) }\end{array}$ & $\begin{array}{l}\text { Okada (1992), Okada and Okada (1988): } \\
\text { the shifts have very strict start and end } \\
\text { times: a different morning shift (same } \\
\text { start time, half the duration) is accepted } \\
\text { on Saturdays } \\
\text { Hung (1991): } 3 \text { slightly overlapping } \\
\text { 10-hour shifts } \\
\text { Weil et al. (1995): } 8 \text {-hour day and evening } \\
\text { shifts and 10-hour night shift }\end{array}$ \\
\hline & Strict Start-End Times & Floating Intervals \\
\hline $\begin{array}{l}\text { Defined length: the intervals } \\
\text { cannot be set by the users }\end{array}$ & & $\begin{array}{l}\text { Bailey and Field (1985): 12-hour shifts } \\
\text { instead of 8-hour shifts; the shifts can } \\
\text { start at any time of the day }\end{array}$ \\
\hline $\begin{array}{l}\text { User definable shifts: the } \\
\text { number of different shifts, } \\
\text { their start and end times and } \\
\text { their length are set by } \\
\text { the users }\end{array}$ & $\begin{array}{l}\text { Meyer auf'm Hofe (1997, 2001) } \\
\text { Meisels and Lusternik (1998) } \\
\text { Schaerf and Meisels (1999) } \\
\text { Burke et al. (2001a, 2001b, 2003), and } \\
\quad \text { Burke, De Causmaecker, and Vanden } \\
\text { Berghe (1999) and De Causmaecker and } \\
\text { Vanden Berghe (2003) } \\
\text { Chiarandini, Schaerf, and Tiozzo (2000) } \\
\text { Kawanaka et al. (2001) } \\
\text { Meisels, Gudes, and Solotorevski (1996) }\end{array}$ & $\begin{array}{l}\text { Tanomaru (1995) } \\
\text { Brusco and Jacobs (1995) } \\
\text { Schaerf and Meisels (1999): allow partial } \\
\text { assignments } \\
\text { Isken and Hancock (1991): variable } \\
\text { starting times instead of } 3 \text { fixed shifts } \\
\text { per day, Isken (Isken, 2004) } \\
\text { Jaumard, Semet, and Vovor (1998): } \\
\text { assumes demand periods that } \\
\text { correspond to the shift times }\end{array}$ \\
\hline
\end{tabular}


Table 11. Possible planning periods

\begin{tabular}{l|l}
\hline $\mathbf{4}$ days & Warner and Prawda (1972): longer periods are not trustworthy with respect to personnel demand forecast \\
\hline $\mathbf{1}$ week & $\begin{array}{l}\text { Aickelin and Dowsland (2000), Aickelin and White (2004) and Dowsland (1998) } \\
\text { Isken (2004) }\end{array}$ \\
\hline $\mathbf{2}$ weeks & $\begin{array}{l}\text { Musa and Saxena (1984) } \\
\text { Blau and Sear (1983) }\end{array}$ \\
\hline $\mathbf{3}$ weeks & Alfares (2000) \\
\hline $\mathbf{2 - 4}$ weeks & $\begin{array}{l}\text { Berrada, Ferland, and Michelon (1996) } \\
\text { Jan, Yamamoto, and Ohuchi (2000): maximum 30 days }\end{array}$ \\
\hline $\mathbf{2 - 6}$ weeks & $\begin{array}{l}\text { Warner (1976) } \\
\text { Miller, Pierskalla, and Rath (1976) }\end{array}$ \\
\hline $\mathbf{1}$ month & $\begin{array}{l}\text { Smith and Wiggins (1977) } \\
\text { Bellanti et al. (2004) } \\
\text { Ikegami and Niwa (2003) } \\
\text { Moz and Pato (2004) }\end{array}$ \\
\hline $\mathbf{1}$ year & \begin{tabular}{l} 
Chan and Weil (2001) \\
\hline User defined
\end{tabular} \\
\hline
\end{tabular}

Table 12. Staff size

\begin{tabular}{|c|c|}
\hline $\begin{array}{l}\text { User definable } \\
\text { fixed number }\end{array}$ & $\begin{array}{l}\text { Ozkarahan and Bailey (1988) } \\
\text { Warner (1976): examples with 19-47 nurses } \\
\text { Miller, Pierskalla, and Rath (1976) } \\
\text { Musa and Saxena (1984): example with } 11 \text { people } \\
\text { Aickelin and Dowsland (2000), Aickelin and White (2004), Dowsland (1998) } \\
\text { Dowsland and Thompson (2000): between } 20 \text { and } 30 \text { nurses; float nurses are assigned when the } \\
\quad \text { workload is too high } \\
\text { Chan and Weil (2001): } 150 \text { people } \\
\text { Jan, Yamamoto, and Ohuchi (2000): maximum } 30 \text { people } \\
\text { Bellanti et al. (2004) } \\
\text { Ikegami and Niwa (2003) } \\
\text { Burke et al. (2001a, 2001b) and Burke, De Causmaecker, and Vanden Berghe (1999) and } \\
\text { De Causmaecker and Vanden Berghe (2003) }\end{array}$ \\
\hline To be minimised & $\begin{array}{l}\text { Arthur and Ravindran (1981); the model relies on an even number of nurses to function properly } \\
\text { Alfares (2000) } \\
\text { Easton and Mansour (1993) }\end{array}$ \\
\hline
\end{tabular}


Table 13. Time related constraints: Capacity

\begin{tabular}{|c|c|c|}
\hline \multicolumn{3}{|c|}{ Finite capacity constraints } \\
\hline Capacity & User definable & Set values \\
\hline $\begin{array}{l}\text { Maximum number } \\
\text { of assignments }\end{array}$ & $\begin{array}{l}\text { Burke et al. (2001a, 2001b, 2003) and } \\
\text { Burke, De Causmaecker, and Vanden Berghe (1999) } \\
\text { and De Causmaecker and Vanden Berghe (2003) } \\
\text { Bellanti et al. (2004) }\end{array}$ & $\begin{array}{l}\text { Meyer auf'm Hofe (2001): } \\
10 \text { per } 14 \text { days, a legal constraint } \\
\text { Li, Lim, and Rodrigues (2003) } \\
\text { Miller, Pierskalla, and Rath (1976): } \\
\text { exact number of assignments: } \\
10 \text { per } 14 \text { days; hard constraint } \\
\text { Kawanaka et al. (2001): restrict } \\
\text { free days to Saturdays, Sundays } \\
\text { and bank holidays }\end{array}$ \\
\hline Overtime & $\begin{array}{l}\text { Burke et al. (2001a, 2001b, 2003) and } \\
\text { Burke, De Causmaecker, and Vanden Berghe (1999) } \\
\text { and De Causmaecker and Vanden Berghe (2003) } \\
\text { Meisels, Gudes, and Solotorevski (1996) }\end{array}$ & $\begin{array}{l}\text { Meyer auf'm Hofe (1997): } \\
\text { minimise overtime } \\
\text { Chen and Yeung (1993) }\end{array}$ \\
\hline $\begin{array}{l}\text { Maximum number of } \\
\text { assignments to a par- } \\
\text { ticular Shift Type }\end{array}$ & $\begin{array}{l}\text { Burke et al. (2001a, 2001b, 2003) and } \\
\text { De Causmaecker and Vanden Berghe (2003) } \\
\text { Ikegami and Niwa (2003) }\end{array}$ & \\
\hline $\begin{array}{l}\text { Maximum number of } \\
\text { shifts per week }\end{array}$ & $\begin{array}{l}\text { Burke et al. (2001a, 2001b, 2003) and } \\
\text { Burke, De Causmaecker, and Vanden Berghe (1999) } \\
\text { and De Causmaecker and Vanden Berghe (2003): } \\
\text { can be set per shift type } \\
\text { Meisels, Gudes, and Solotorevski (1996) } \\
\text { Berrada, Ferland, and Michelon (1996): } \\
\text { hard constraint; restricted version } \\
\text { limiting the assignments per week }\end{array}$ & \\
\hline
\end{tabular}

their contract (involving the time related constraints). It generally means that all the personnel members have a full time contract. The second part of the table refers to mixed approaches in which full time and half time contracts are combined. This is probably still not applicable to most real problems. Models that allow the users to set all the parameters related to contracts and personal constraints are grouped in the next part of the table. They are all more oriented towards applicability in real hospitals. The lowest level of the table shows the papers that mention 'float' nurses. It is often the case that a temporary personnel shortage is solved by moving people from another ward. The references in this table are thus organised from top to bottom in groups of increasing complexity.

It is also shown in Table 8 that in case of personnel shortage, many hospitals make use of a group of 'float' nurses, to assist on a temporary basis.

Most researchers are aware of regular changes in coverage constraints. This is one of the reasons why pure cyclical schedules are generally not workable. In Table 9 , we have grouped the approaches in categories of flexibility. The top of the table shows the least flexible papers with respect to changes. 
Table 14. Time related constraints: Personal preferences

\begin{tabular}{|c|c|}
\hline \multicolumn{2}{|r|}{ Personal preferences } \\
\hline $\begin{array}{l}\text { Gener al } \\
\quad \text { (unspecified) }\end{array}$ & $\begin{array}{l}\text { Meyer auf'm Hofe (1997) } \\
\text { Warner (Warner, 1976) }\end{array}$ \\
\hline Days off & $\begin{array}{l}\text { Burke et al. (2001a, 2001b, 2003) and Burke, De Causmaecker, and Vanden Berghe (1999) and } \\
\text { De Causmaecker and Vanden Berghe (2003) with extra information about the type of absence } \\
\text { (holiday, illness, educational) } \\
\text { Miller, Pierskalla, and Rath (1976): special requests can even } \\
\text { overrule some of the feasibility constraints } \\
\text { Chen and Yeung (1993) } \\
\text { Berrada, Ferland, and Michelon (1996) } \\
\text { Kawanaka et al. (2001) } \\
\text { Okada (1992), Okada and Okada (1988) } \\
\text { Meisels, Gudes, and Solotorevski (1996) } \\
\text { Ikegami and Niwa (2003) } \\
\text { Bellanti et al. (2004) }\end{array}$ \\
\hline Shifts off & $\begin{array}{l}\text { Burke et al. (2001a, 2001b, 2003) and Burke, De Causmaecker, and Vanden Berghe (1999) and } \\
\text { De Causmaecker and Vanden Berghe (2003) }\end{array}$ \\
\hline Days on & $\begin{array}{l}\text { Burke et al. (2001a, 2001b, 2003) and Burke, De Causmaecker, and Vanden Berghe (1999) and } \\
\text { De Causmaecker and Vanden Berghe (2003): enable defining working days without specifying } \\
\text { a particular shift type } \\
\text { Berrada, Ferland, and Michelon (1996) allow to ask for specific working days }\end{array}$ \\
\hline Shift on & $\begin{array}{l}\text { Burke et al. (2001b) } \\
\text { Meisels, Gudes, and Solotorevski (1996) } \\
\text { Bellanti et al. (2004) } \\
\text { Li, Lim, and Rodrigues (2003) }\end{array}$ \\
\hline Shift patterns & Dowsland and Thompson (2000) \\
\hline Shift sequences & Moz and Pato (2004) \\
\hline
\end{tabular}

Warner and Prawda (1972) predict the personnel requirements for the next few days. The personnel requirements are nearly always expressed as the number of people required per shift type or even per day. Modelling very detailed, hardly varying coverage constraints generally causes no problem for generating solutions. Miller, Pierskalla, and Rath (1976), Burke et al. (2001c), and Meyer auf'm Hofe $(1997,2001)$ are among those that leave a large part of initiative to the schedulers. Burke et al. (2001c) tackle the problem in a flexible way, as a result of feedback from the users of their software system in several hospitals. Not only is the number of possible shift types higher than in most problems encountered, but also the approach to compose a schedule with different combinations of shift types is unusual.

The last column of the table groups papers in which the coverage constraints are defined as a range between minimum and maximum coverage. Such a range is more useful in practice than very strict numbers. 
Table 15. Time related constraints: Consecutiveness constraints (1)

\begin{tabular}{|c|c|c|}
\hline \multicolumn{3}{|c|}{ Consecutiveness constraints (1) } \\
\hline Consecutiveness & User definable & Set values \\
\hline $\begin{array}{l}\text { Maximum number } \\
\text { of consecutive } \\
\text { days }\end{array}$ & $\begin{array}{l}\text { Miller, Pierskalla, and Rath (1976): } \\
\text { non-binding constraint; non-binding } \\
\text { maximum < feasibility maximum } \\
\text { Okada (1992), Okada and Okada (1988) } \\
\text { Berrada, Ferland, and Michelon (1996) } \\
\text { Burke et al. (2001a, 2001b, 2003) and } \\
\text { Burke, De Causmaecker, and Vanden Berghe (1999) } \\
\text { and De Causmaecker and Vanden Berghe (2003) } \\
\text { Warner (1976): some workstretches allow } \\
\text { for a } 3 \text { or } 4 \text { day weekend } \\
\text { Weil et al. (1995) } \\
\text { Bellanti et al. (2004) }\end{array}$ & $\begin{array}{l}\text { Arthur and Ravindran (1981): } \\
\text { implicitly restricted to } 12 \text { because } \\
\text { every other weekend is free } \\
\text { Chen and Yeung (1993): restricted to } 6 \\
\text { Warner (1976) } \\
\text { Miller, Pierskalla, and Rath (1976): } \\
\text { feasibility constraint: } \\
\text { feasibility maximum } \\
\text { Burns (1978): maximum } 6\end{array}$ \\
\hline $\begin{array}{l}\text { Minimum number } \\
\text { of consecutive } \\
\text { days }\end{array}$ & $\begin{array}{l}\text { Burke et al. (2001a, 2001b, 2003) and } \\
\text { Burke, De Causmaecker, and Vanden Berghe (1999) } \\
\text { and De Causmaecker and Vanden Berghe (2003) } \\
\text { Miller, Pierskalla, and Rath (1976): } \\
\text { non-binding constraint: non-binding } \\
\text { minimum > feasibility minimum } \\
\text { Bellanti et al. (2004) } \\
\text { Chen and Yeung (1993): minimum 2; } \\
\text { on/off patterns are avoided } \\
\text { Warner (1976): off/on/off days are avoided }\end{array}$ & $\begin{array}{l}\text { Weil et al. (1995): minimum 2; } \\
\text { no isolated days on } \\
\text { Miller, Pierskalla, and Rath (1976): } \\
\text { feasibility constraint: } \\
\text { feasibility minimum } \\
\text { Warner (1976): no isolated working days } \\
\text { Berrada, Ferland, and Michelon (1996): } \\
\text { minimum 2; no on/off patterns } \\
\text { Jaszkiewicz (1997) grouping working days }\end{array}$ \\
\hline $\begin{array}{l}\text { Number of } \\
\text { consecutive days }\end{array}$ & & $\begin{array}{l}\text { Aickelin and Dowsland (2000): a } \\
\text { set number, incorporated in } \\
\text { the shift pattern cost }\end{array}$ \\
\hline $\begin{array}{l}\text { Maximum number } \\
\text { of consecutive } \\
\text { free days }\end{array}$ & $\begin{array}{l}\text { Burke et al. (2001a, 2001b, 2003) and } \\
\text { Burke, De Causmaecker, and Vanden Berghe (1999) } \\
\text { and De Causmaecker and Vanden Berghe (2003) } \\
\text { Moz and Pato (2004) }\end{array}$ & $\begin{array}{l}\text { Miller, Pierskalla, and Rath (1976): } \\
\text { no patterns containing } \\
4 \text { consecutive days off } \\
\text { Jaszkiewicz (1997) grouping free days }\end{array}$ \\
\hline
\end{tabular}

Some approaches generate schedules that only consist of days off and on. In these cases, the next step in the process, the assignment of actual shifts to people, is left for a head nurse to do manually. These papers are grouped in the upper part of Table 10. The possible shifts are strictly distinct since there is no overlapping between an assignment and a free day. It is very common in nurse rostering to consider three different shift types (the second group in Table 10). We found many examples of models with three strictly distinct shift types but also some that allow an overlap in time between the shifts. However, the latter are not necessarily as flexible as might be required because they have set start and end times for all the three shift types.

Algorithms developed for use in practical healthcare environments do not work with three strictly distinct shift types (see the lower half of Table 10). The activities in hospitals are so varied 
Table 16. Time related constraints: Consecutiveness constraints (2)

\begin{tabular}{|c|c|c|}
\hline \multicolumn{3}{|c|}{ Consecutiveness constraints (2) } \\
\hline Consecutiveness & User definable & Set values \\
\hline $\begin{array}{l}\text { Minimum number of } \\
\text { consecutive free days }\end{array}$ & $\begin{array}{l}\text { Burke et al. (2001a, 2001b, 2003) and } \\
\quad \text { Burke, De Causmaecker, and Vanden Berghe (1999) } \\
\text { and De Causmaecker and Vanden Berghe (2003) } \\
\text { Warner (1976): minimum 2; no isolated } \\
\text { free days } \\
\text { Bellanti et al. (2004) }\end{array}$ & $\begin{array}{l}\text { Aickelin and Dowsland (2000): } \\
\text { incorporated in the shift } \\
\text { pattern cost } \\
\text { Weil et al. (1995): minimum 2; no } \\
\text { isolated free days } \\
\text { Valouxis and Housos (2000) } \\
\text { Baker (1974): exactly } 3 \text { consecutive } \\
\text { free days per week } \\
\text { Chen and Yeung (1993): minimum 2; } \\
\text { on/off patterns are avoided } \\
\text { Miller, Pierskalla, and Rath (1976): } \\
\text { no on/off/on patterns, } \\
\text { non-binding constraint } \\
\text { Meyer auf'm Hofe (1997): preference } \\
\text { of working time models } \\
\text { (common sequences of working } \\
\text { shifts), usually } 2 \text { weeks long }\end{array}$ \\
\hline $\begin{array}{l}\text { Patterns (these are } \\
\text { cyclical time related } \\
\text { constraints imposed } \\
\text { on non-cyclical } \\
\text { schedules) }\end{array}$ & $\begin{array}{l}\text { Warner (1976): restricted number of } \\
2 \text { week patterns for day/night weeks } \\
\text { and alternating free weekends; } \\
\text { nurses specify their 'aversion' } \\
\text { to certain patterns } \\
\text { Burke et al. (2001a, 2001b, 2003) and } \\
\text { Burke, De Causmaecker, and Vanden Berghe (1999) } \\
\text { and De Causmaecker and Vanden Berghe (2003) }\end{array}$ & $\begin{array}{l}\text { Berrada, Ferland, and Michelon } \\
\text { (1996): hard constraint; restricted } \\
\text { constraint on weekend } \\
\text { working patterns } \\
\text { Aickelin and Dowsland (2000): } \\
\text { rotate night shifts } \\
\text { and weekend work } \\
\text { Miller, Pierskalla, and Rath (1976): } \\
\text { days on/off patterns only; } \\
\text { less possible patterns than } \\
\text { (Warner, 1976) } \\
\text { Musa and Saxena (1984): nurses } \\
\text { chose which one of } 2 \\
\text { alternative weekends to be free } \\
\text { Berrada, Ferland, and Michelon } \\
\text { (1996): minimum 2, another } \\
\text { aim is to group days off } \\
\text { Arthur and Ravindran (1981): } \\
5 \text { possible shift patterns }\end{array}$ \\
\hline
\end{tabular}

that a large number of user-definable shifts is usually allowed. In Burke et al. (2001c) start and end times can even be personal for some practical reasons as a result of negotiation between an individual and the hospital manager.

Short planning periods are much easier to generate schedules for. It can be an option to split the period into smaller intervals and to combine the schedules afterwards. This will lead to sub-optimal 
Table 17. Time related constraints: Consecutiveness constraints (3)

\begin{tabular}{|c|c|c|}
\hline \multicolumn{3}{|c|}{ Consecutiveness constraints (3) } \\
\hline Consecutiveness & User definable & Set values \\
\hline $\begin{array}{l}\text { Free days after night } \\
\text { shifts }\end{array}$ & $\begin{array}{l}\text { Burke et al. (2001a, 2001b, 2003) and Burke, } \\
\text { De Causmaecker, and Vanden Berghe (1999) and } \\
\text { De Causmaecker and Vanden Berghe (2003): minimum } \\
\text { number of free days after overnight shifts } \\
\text { Ikegami and Niwa (2003) } \\
\text { Bellanti et al. (2004) }\end{array}$ & $\begin{array}{l}\text { Okada (1992), Okada and Okada } \\
\text { (1988): appropriate interval } \\
\text { between series of night } \\
\text { attendances }\end{array}$ \\
\hline $\begin{array}{l}\text { No night shift } \\
\text { before day off }\end{array}$ & $\begin{array}{l}\text { Burke et al. (2001a, 2001b, 2003) and Burke, } \\
\text { De Causmaecker, and Vanden Berghe (1999) and } \\
\text { De Causmaecker and Vanden Berghe (2003) }\end{array}$ & \\
\hline $\begin{array}{l}\text { Time between } \\
\text { assignments }\end{array}$ & $\begin{array}{l}\text { Burke et al. (2001a, 2001b, 2003) and Burke, } \\
\text { De Causmaecker, and Vanden Berghe (1999) and } \\
\text { De Causmaecker and Vanden Berghe (2003): minimum } \\
\text { rest time per shift } \\
\text { Meyer auf'm Hofe (1997, 2001): obligatory and preferred } \\
\text { breaks between assignments } \\
\text { Isken (2004) }\end{array}$ & $\begin{array}{l}\text { Kawanaka et al. (2001): no early or } \\
\text { day shift after a night shift } \\
\text { Warner (1976): not less than } 16 \\
\text { hours between two assignments }\end{array}$ \\
\hline Consecutive shifts & $\begin{array}{l}\text { Burke et al. (2001a, 2001b, 2003) and Burke, } \\
\text { De Causmaecker, and Vanden Berghe (1999) and } \\
\text { De Causmaecker and Vanden Berghe (2003): allow or } \\
\text { forbid shift sequences on consecutive days } \\
\text { Meyer auf'm Hofe (2001): minimum and preferred rest } \\
\text { time between shifts } \\
\text { Ikegami and Niwa (2003) }\end{array}$ & $\begin{array}{l}\text { Kawanaka et al. (2001): no early or } \\
\quad \text { day shift after a night } \\
\text { Bellanti et al. (2004): no morning } \\
\quad \text { shift after an afternoon } \\
\text { Moz and Pato (2004) }\end{array}$ \\
\hline $\begin{array}{l}\text { Sequences of shift } \\
\text { types }\end{array}$ & $\begin{array}{l}\text { Burke et al. (2001b): flexible definition for each shift type } \\
\text { Ikegami and Niwa (2003) }\end{array}$ & $\begin{array}{l}\text { Meyer auf'm Hofe (2001): } \\
\text { undesired sequences of work and } \\
\text { free time }\end{array}$ \\
\hline $\begin{array}{l}\text { Mixture of } \\
\text { day-night shifts } \\
\text { per Week }\end{array}$ & & Aickelin and Dowsland (2000) \\
\hline
\end{tabular}

solutions in nearly all the cases. Table 11 gives examples of some of the approaches discussed in this article. The first example (Warner and Prawda, 1972), has the shortest planning period of all. Forecasting the demands is not possible for a period longer than 4 days in that model. The short planning period leads to a rather simple rostering problem. However, it is not a very good idea not to fix the coverage constraints long beforehand because that does not correspond to the needs in real hospitals. The next rows in Table 11 present other approaches with fixed and semi-fixed planning periods. More complex models, with longer planning periods, are listed lower down in the table. 
Table 18. Time related constraints: Balance the workload

\begin{tabular}{|c|c|c|}
\hline \multicolumn{3}{|c|}{ Balance the workload } \\
\hline Balance & User definable & Set values \\
\hline \multirow[t]{10}{*}{ Balance } & $\begin{array}{l}\text { Burke et al. (2001a, 2001b, 2003) and Burke, } \\
\text { De Causmaecker, and Vanden Berghe (1999) } \\
\text { and De Causmaecker and Vanden Berghe } \\
\text { (2003) }\end{array}$ & $\begin{array}{l}\text { Jaszkiewicz (1997): distribute the shifts evenly among } \\
\text { nurses }\end{array}$ \\
\hline & $\begin{array}{l}\text { Meyer auf'm Hofe (2001): balance working time } \\
\text { accounts }\end{array}$ & $\begin{array}{l}\text { Okada (1992), Okada and Okada (1988): balance night } \\
\text { shifts, work on Sundays and work on bank holidays } \\
\text { per month and per year }\end{array}$ \\
\hline & $\begin{array}{l}\text { Miller, Pierskalla, and Rath (1976): individual } \\
\text { 'aversion' coefficient for violations of } \\
\text { non-binding constraints }\end{array}$ & $\begin{array}{l}\text { Okada (1992), Okada and Okada (1988): night shifts } \\
\text { evenly distributed per day of the week (per person) }\end{array}$ \\
\hline & $\begin{array}{l}\text { Warner (1976): nurses and entire wards } \\
\text { distribute a limited amount of penalty weights } \\
\text { to constraints }\end{array}$ & $\begin{array}{l}\text { Chiarandini, Schaerf, and Tiozzo (2000): long-term fair } \\
\text { distribution of undesired shifts as well as a } \\
\text { distribution among personnel members of violations } \\
\text { on the number of assignments per week }\end{array}$ \\
\hline & Chen and Yeung (1993): some fairness measures & $\begin{array}{l}\text { Aickelin and White (2004): evenly distribute unsatisfied } \\
\text { requests and unpopular shifts }\end{array}$ \\
\hline & & Blau $(1985)$ \\
\hline & & Ikegami and Niwa (2003) \\
\hline & & $\begin{array}{l}\text { Bellanti et al. (2004): balance days off in weekends, } \\
\text { balance shifts }\end{array}$ \\
\hline & & Kawanaka et al. (2001): balance of shifts \\
\hline & & Dowsland and Thompson (2000) \\
\hline
\end{tabular}

The number of personnel members assigned to a hospital ward can vary from less than 10 to well over 100. In the cases where the problem cannot be split into sub-problems, the algorithms must be powerful enough to solve problems with widely varying parameters. Table 12 presents an overview of the models with respect to staff size. The upper half of the table shows a list of models in which the user can set the number of nurses to be scheduled. The lower part groups problems that attempt to minimise the staff size in a ward. Of course, setting the number of personnel belongs more to staffing than to nurse rostering.

Tables 13 to 20 present a list of time related constraints. Some researchers set strict values for the constraints, whereas others let them be user definable. A few authors apply constraint programming techniques in their model (e.g. Meyer auf'm Hofe, 1997, 2001; Meisels, Gudes, and Solotorevski, 1996). Others have set up a new formal evaluation method for a very extensive set of modifiable time-related constraints (e.g. Burke et al., 2001b). If we compare the tables listing the time related constraints (Table 13 to 20) with Table 1, it is clear that the most flexible definitions exist in the approaches that are applicable in real scheduling situations.

Table 13 classifies approaches with capacity constraints. We distinguish models that impose set values (last column) and models with user definable capacity constraints (middle column). The latter obviously lead to more complex models. All the constraints restricting the amount of work that 
Table 19. Time related constraints: Weekends

\begin{tabular}{|c|c|c|}
\hline \multicolumn{3}{|c|}{ Weekends } \\
\hline Weekends & User definable & Set values \\
\hline $\begin{array}{l}\text { Weekends in } \mathrm{x} \\
\text { weeks }\end{array}$ & $\begin{array}{l}\text { Burke et al. (2001a, 2001b, 2003) and Burke, } \\
\text { De Causmaecker, and Vanden Berghe (1999) and } \\
\text { De Causmaecker and Vanden Berghe (2003) } \\
\text { Miller, Pierskalla, and Rath (1976): per } 4 \text { or } 6 \text { weeks }\end{array}$ & \\
\hline $\begin{array}{l}\text { Complete weekends } \\
\text { and extended } \\
\text { weekends }\end{array}$ & $\begin{array}{l}\text { Burke et al. (2001a, 2001b, 2003) and Burke, } \\
\text { De Causmaecker, and Vanden Berghe (1999) and } \\
\text { De Causmaecker and Vanden Berghe (2003): } \\
\text { weekends can be extended with Friday and/or } \\
\text { Monday } \\
\text { Miller, Pierskalla, and Rath (1976) } \\
\text { Warner (1976): some work stretches allow for a } 3 \text { or } \\
4 \text { days weekend }\end{array}$ & $\begin{array}{l}\text { Berrada, Ferland, and Michelon (1996) } \\
\text { encourage to extend the weekends }\end{array}$ \\
\hline $\begin{array}{l}\text { Compensation of } \\
\text { weekend work }\end{array}$ & Meyer auf'm Hofe (2001) & $\begin{array}{l}\text { Okada (1992), Okada and Okada (1988): } \\
\text { days off to compensate for work on } \\
\text { Sunday and half days off to } \\
\text { compensate for 8-hours Saturday work; } \\
\text { preferably within that week }\end{array}$ \\
\hline $\begin{array}{l}\text { Number of } \\
\text { consecutive } \\
\text { weekends }\end{array}$ & $\begin{array}{l}\text { Warner (1976) alternates free weekends (e.g. one } \\
\text { every } 2 \text { or } 3 \text { weeks) } \\
\text { Miller, Pierskalla, and Rath (1976) } \\
\text { Musa and Saxena (1984): alternate free and } \\
\text { working weekends, individual nurses can choose } \\
\text { which weekends are free } \\
\text { Burke et al. (2001a, 2001b, 2003) and Burke, } \\
\text { De Causmaecker, and Vanden Berghe (1999) and } \\
\text { De Causmaecker and Vanden Berghe (2003) }\end{array}$ & $\begin{array}{l}\text { Arthur and Ravindran (1981) strictly } \\
\text { schedule every other weekend off } \\
\text { Burns (1978): alternate weekends off }\end{array}$ \\
\hline
\end{tabular}

nurses carry out are considered: maximum number of assignments, overtime, maximum number of assignments per week or for particular shift types. A few models include all the listed constraints.

Table 14 groups approaches that allow nurses to set a few personal preferences. We do not include recurring preferences (such as preferably only weekend and night work) because, in our experience, these tend to be arranged in the contracts. Some constraints are classified as 'general', if the paper does not specify what they mean. We have identified 4 specific types of personal preferences; requests for particular days on and off, and requests to work certain shifts on particular days.

Consecutiveness is a typical personnel rostering constraint. We have collected a large number of such constraints and grouped them in Tables 15 to 17. The first 3 constraints (Table 15) restrict the number of consecutive working days. Some flexibly allow the definition of a range between a minimum and maximum but Aickelin and Dowsland (2000) set a fixed number. Again, the right column of the table groups the least flexible approaches, in which the values are set by the developers. 
Table 20. Time related constraints: Others

\begin{tabular}{|c|c|c|}
\hline \multicolumn{3}{|c|}{ Other constraints } \\
\hline Other constraints & User definable & Set values \\
\hline Preference days/nights & & $\begin{array}{l}\text { Aickelin and Dowsland (2000), Dowsland and } \\
\text { Thompson (2000) }\end{array}$ \\
\hline Working history & $\begin{array}{l}\text { Burke et al. (2001a, 2001b, 2003), Burke, } \\
\text { De Causmaecker, and Vanden Berghe } \\
\text { (1999) and De Causmaecker and Vanden } \\
\text { Berghe (2003): influence on most constraint } \\
\text { evaluations } \\
\text { Miller et al. (1976): historical schedule quality } \\
\text { versus personal preferences } \\
\text { Ikegami and Niwa (2003) }\end{array}$ & $\begin{array}{l}\text { Aickelin and Dowsland (2000): the cost of the } \\
\text { previous period is added to the current one, } \\
\text { with a maximum of } 100\end{array}$ \\
\hline $\begin{array}{l}\text { Changes in shifts on } \\
\text { consecutive days }\end{array}$ & & $\begin{array}{l}\text { Jaszkiewicz (1997): changes should be } \\
\text { minimised }\end{array}$ \\
\hline $\begin{array}{l}\text { Maximum consecutive } \\
\text { on/off/on patterns }\end{array}$ & & Miller et al. (1976): feasibility constraint \\
\hline $\begin{array}{l}\text { People working together } \\
\text { or not }\end{array}$ & $\begin{array}{l}\text { Burke et al. (2001a, 2001b, 2003) and Burke, } \\
\text { De Causmaecker, and Vanden Berghe } \\
\text { (1999) and De Causmaecker and Vanden } \\
\text { Berghe (2003) } \\
\text { Jan et al. (2000): nurses have the right to select } \\
\text { preferred partners }\end{array}$ & $\begin{array}{l}\text { Okada (1992), Okada and Okada (1988): } \\
\text { maximise the number of different personnel } \\
\text { members for weekend and night work }\end{array}$ \\
\hline
\end{tabular}

We also identified constraints on consecutive free days (bottom of Table 15 and top of Table 16). Models in which the users can freely set these constraints are rare (middle column). Patterns are cyclical time related constraints that are imposed on a non-cyclical schedule. Such constraints are dealt with by Warner (1976), Burke et al. (2001a, 2001b, 2003), Burke, De Causmaecker, and Vanden Berghe (1999), and De Causmaecker and Vanden Berghe (2003). The majority of developers apply set values (right hand column).

There must be free time between consecutive assignments. Free time is user definable and it can differ per shift type (e.g. Burke et al. 2001a, 2001b, 2003; Burke, De Causmaecker, and Vanden Berghe, 1999, De Causmaecker and Vanden Berghe, 2003). Meyer auf'm Hofe (2001) applies a range (between obligatory and preferred) of spare time that is allowed. Some consecutiveness constraints that arrange sequences of shift types are grouped in the last rows of Table 17. A very interesting type of constraint evaluates the balance of workload among personnel. Again, we distinguish between more flexible models (middle column) and models that do not allow variance in the preset values (right hand column).

Weekend constraints cannot be ignored in personnel rostering. It is worth noting that the perception of well organised weekends (from anecdotal evidence) appears to be relatively more important for individual nurses than the satisfaction of any other type of time related constraint. Perhaps this is not so surprising. We have subdivided the constraints that relate to weekends into 4 groups 
in Table 19. The middle column presents the more flexible approaches and the last column groups the papers in which the constraints are determined beforehand by the developers.

Table 20 briefly describes constraints that did not match any of the constraint types described in Tables 13 to 19. We did not classify the constraint in the first row among the personal preference constraints of Table 14 because this one is not an occasional preference but rather one that determines contractual aspects (e.g. always free Wednesday afternoons). Jaszkiewicz (1997) addresses the constraint that changes in shift types on consecutive days should be minimised. Other approaches apply a combination of consecutiveness constraints to reach that objective (see also Tables 15 to 17 ).

Finally, a few models incorporate a constraint on whether particular personnel members should work together or not. Such constraints do not appear in the more theoretical models.

\section{REFERENCES}

Aarts, E. and J. K. Lenstra, Local Search in Combinatorial Optimization, Wiley, ISBN 0-471-94822-5, 1997.

Abernathy, W. J., N. Baloff, J. C. Hershey, and S. Wandel, "A three-stage manpower planning and scheduling model-A service-sector example,” Operations Research, 22, 693-711 (1973).

Abdennadher, S. and H. Schlenker, "INTERDIP - An interactive constraint based nurse scheduler," in Proceedings, Practical Applications Constraint Technology and Logic Programming, 1999a.

Abdennadher, S. and H. Schlenker, "Nurse scheduling using constraint logic programming," in Proceedings of the Eleventh Conference on Innovative Applications of Artificial Intelligence, Menlo Park, California, AAAI Press, 1999 b, pp. 838-843.

Aickelin, U. and K. Dowsland, "An indirect genetic algorithm for a nurse scheduling problem," Computers and Operations Research, 31(5), 761-778 (2004).

Aickelin, U. and K. Dowsland, "Exploiting problem structure in a genetic algorithm approach to a nurse rostering problem," Journal of Scheduling, 3(3), 139-153 (2000).

Aickelin, U. and P. White, "Building better nurse scheduling algorithms," Annals of Operations Research, 128, 159-177 (2004).

Akerstedt, T., "Adjustment of physiological circadian rhythms and sleep-wake cycle to shiftwork," in S. Folkard and T.H. Monk (eds.), Hours of Work: Temporal Factors in Work-Scheduling, John Wiley and Sons, Chichester, UK, 1985, pp. $185-198$.

Alfares, H. K., "Days-off employee scheduling over a three-week work cycle," in E.K. Burke and W. Erben (eds.), Proceedings of the 3rd International Conference on the Practice and Theory of Automated Timetabling, ISBN 3-00-003866-3, 2000, pp. 251-258.

Alfares, H. K., "Four-day workweek scheduling with two or three consecutive days off," Journal of Mathematical Modelling and Algorithms, 2, 67-80 (2003).

Anzai, M. and Y. Miura, "Computer program for quick work scheduling of nursing staff,” Medical Informatics, 12, 43-52 (1987).

Arthur, J. and A. Ravindran, "A multiple objective nurse scheduling model," AIIE Transactions, 13(1), 55-60 (1981).

Bailey, J. and J. Field, "Personnel scheduling with flexshift models," Journal of Operations Management, 5, 327-338 (1985).

Baker, K., "Scheduling a full-time workforce to meet cyclic staffing requirements," Management Science, 20(12), 1561-1568 (1974).

Bechtold, S. E., M. J. Brusco, and M. J. Showalter, “A comparative evaluation of labor tour scheduling methods,” Decision Sciences, 22, 683-699 (1991).

Bechtold, S. E. and L. W. Jacobs, "Implicit modeling of flexible break assignments in optimal shift scheduling," Management Science, 36, 1339-1351 (1990).

Bechtold, S. E. and M. J. Showalter, "A methodology for labor scheduling in a service operation system," Decision Sciences, 18, 89-107 (1987)

Bell, P. C., G. Hay, and Y. Liang, "A visual interactive decision support system for workforce (Nurse) scheduling,” Information Systems and Operational Research, 24(2), 133-144 (1986).

Bellanti, F., G. Carello, F. Della Croce, and R. Tadei, "A greedy-based neighborhood search approach to a nurse rostering problem," European Journal of Operational Research, 153(1), 28-40 (2004).

Berrada, I., J. Ferland, and P. Michelon, "A multi-objective approach to nurse scheduling with both hard and soft constraints," Socio-Economic Planning Science, 30, 183-193 (1996). 
Blau, R., "Multishift personnel scheduling with a microcomputer," Personnel Administrator, 20(7), 43-58 (1985).

Blau, R. and A. Sear, "Nurse scheduling with a microcomputer," Journal of Ambulance Care Management, 1-13 (1983).

Bradley, D. and J. Martin, "Continuous personnel scheduling algorithms: A literature review," Journal of the Society of Health Systems, 2, 8-23 (1990).

Brusco, M. J. and L. W. Jacobs, "Cost analysis of alternative formulations for personnel scheduling in continuously operating organisations," European Journal of Operational Research, 86, 249-261 (1995).

Brusco, M. J., L. W. Jacobs, R. J. Bongiorno, D. V. Lyons, and B. Tang, "Improving personnel scheduling at airline stations," Operations Research, 43(5), 741-751 (1995).

Burke, E. K., Y. Bykov, J. P. Newall, and S. Petrovic, "A time-predefined local search approach to exam timetabling problems," IIE Transactions on Operations Engineering, 36, 1-19 (2004).

Burke, E. K., Y. Bykov, and S. Petrovic, "A multicriteria approach to examination timetabling," in E. K. Burke and W. Erben (eds.), Practice and Theory of Automated Timetabling, Third International Conference, Konstanz, Springer Lecture Notes in Computer Science, vol. 2079, 2001, pp. 118-131.

Burke, E. K., P. Cowling, P. De Causmaecker, and G. Vanden Berghe, "A memetic approach to the nurse rostering problem," Applied Intelligence, 15(3), 199-214 (2001a).

Burke, E. K., P. De Causmaecker, S. Petrovic, and G. Vanden Berghe, "A multi criteria metaheuristic approach to Nurse rostering," in Proceedings of Congress on Evolutionary Computation, CEC2002, Honolulu, IEEE Press, 2002, pp. 11971202.

Burke, E. K., P. De Causmaecker, S. Petrovic, and G. Vanden Berghe, "Fitness evaluation for Nurse scheduling problems," in Proceedings of Congress on Evolutionary Computation, CEC2001, Seoul, IEEE Press, 2001b, pp. 1139-1146.

Burke, E. K., P. De Causmaecker, S. Petrovic, and G. Vanden Berghe, "Metaheuristics for handling time internal coverage constraints in nurse scheduling," Working paper KaHo Sint-Lieven, 2001c.

Burke, E. K., P. De Causmaecker, S. Petrovic, and G. Vanden Berghe, "Variable neighbourhood search for Nurse rostering problems," in Mauricio G. C. Resende and Jorge Pinho de Sousa (eds.), Metaheuristics: Computer Decision-Making Chapter 7, 2003, Kluwer, pp. 153-172.

Burke, E. K., P. De Causmaecker, and G. Vanden Berghe, "A hybrid tabu search algorithm for the Nurse rostering problem," in B. McKay et al. (eds.), Simulated Evolution and Learning, Springer, Lecture Notes in Artificial Intelligence, vol. 1585, Springer, 1999, pp. 187-194.

Burke, E. K., P. De Causmaecker, and G. Vanden Berghe, "Novel metaheuristic approaches to Nurse rostering problems in Belgian hospitals," in J. Leung (ed.), Handbook of Scheduling: Algorithms, Models and Performance Analysis, Chapter 44, CRC Press, 2004, pp. 44.1-44.18.

Burke, E. K. and J. P. Newall, "A multi-stage evolutionary algorithm for the timetabling problem," IEEE Transactions on Evolutionary Computation, 3(1), 64-73 (1999).

Burns, R. N., "Manpower scheduling with variable demands and alternate weekends off," INFOR, 16(2), 101-111 (1978).

Burns, R. N. and G. J. Koop, "A modular approach to optimal multiple-shift manpower scheduling," Operations Research, 35(1), 100-110 (1987).

Carter, M. W., “A decomposition algorithm for practical timetabling problems," Dept. Industrial Engineering, University of Toronto, Working Paper 83-06, April 1983.

Chan, P. and G. Weil, "Cyclical staff scheduling using constraint logic programming," in E. K. Burke and W. Erben (eds.), Practice and Theory of Automated Timetabling, Third International Conference, Konstanz, Springer, Lecture Notes in Computer Science, vol. 2079, 2001, pp. 159-175.

Cheang, B., H. Li, A. Lim, and B. Rodrigues, "Nurse rostering problems-a bibiographic survey," European Journal of Operational Research, 151, 447-460 (2003).

Chen, J.-G. and T. Yeung, "Development of a hybrid expert system for Nurse shift scheduling," Journal of Industrial Ergonomics, 9(4), 315-328 (1992).

Chen, J.-G. and T. Yeung, "Hybrid expert system approach to Nurse scheduling," Computers in Nursing, 183-192 (1993).

Cheng, B. M. W., J. H. M. Lee, and J. C. K. Wu, "A constraint-based Nurse rostering system using a redundant modelling approach," in IEEE Proceedings of the 8th International Conference on Tools with Artificial Intelligence (TAI96) Toulouse, 1996, pp. 140-148.

Cheng, B. M. W., J. H. M. Lee, and J. C. K. Wu, "A nurse rostering system using constraint programming and redundant modeling," IEEE Transactions in Information Technology in Biomedicine, 1(1), 44-54 (1997).

Chiarandini, M., A. Schaerf, and F. Tiozzo, "Solving employee timetabling problems with flexible workload using Tabu search," in E. K. Burke and W. Erben (eds.), Proceedings of the 3rd International Conference on the Practice and Theory of Automated Timetabling, ISBN 3-00-003866-3, 2000, pp. 298-302. 
Darmoni, S. J., A. Fajner, N. Mahe, A. Leforestier, O. Stelian, M. Vondracek, and M. Baldenweck, "Horoplan: Computerassisted nurse scheduling using constraint based programming," Journal of the Society for Health Systems, 5, 41-54 (1995).

De Causmaecker, P. and G. Vanden Berghe, "Relaxation of coverage constraints in hospital personnel rostering," in E. K. Burke and P. De Causmaecker (eds.), Practice and Theory of Automated Timetabling, Fourth International Conference, Gent, Springer, Lecture Notes in Computer Science, vol. 2740, 2003, pp. 129-147.

Decker, K. and J. Li, "Coordinated hospital patient scheduling," in Proceedings of the Third International Conference on Multi-Agent Systems (ICMAS98), Paris, 1998, pp. 104-111.

de Vries, G., "Nursing workload measurement as management information," European Journal of Operational Research, 29, 199-208 (1987).

Dowsland, K., "Nurse scheduling with Tabu search and strategic oscillation," European Journal of Operations Research, 106, 393-407 (1998).

Dowsland, K. A. and J. M. Thompson, "Solving a nurse scheduling problem with knapsacks, networks and tabu search," Journal of the Operational Research Society, 51, 825-833 (2000).

Draeger, M., "An emergency department simulation model used to evaluate alternative Nurse staffing and patient population scenarios," in J. J. Swain, D. Goldsman, R. C. Crain, and J. R. Wilson (eds.), Winter Simulation Conference Proceedings, IEEE, Arlington, VA., 1992, pp. 1057-1064.

Easton, F. and N. Mansour, "A distributed genetic algorithm for employee staffing and scheduling problems," in International Conference on Genetic Algorithms, San Mateo, 1993, pp. 360-367.

Easton, F., D. Rossin, and W. Borders, "Analysis of alternative scheduling policies for hospital Nurses," Production and Operations Management, 1(2), 159-174 (1992).

Easton, F. and D. Rossin, "Sufficient working subsets for the tour scheduling problem," Management Science, 37, 1441-1451 (1991).

Ernst, A. T., H. Jiang, M. Krishnamoorthy, and D. Sier, "Staff scheduling and rostering: A review of applications, methods and models," European Journal of Operational Research, 153(1), 3-27 (2004).

Franz, L. S., H. M. Baker, G. K. Leong, and T. R. Rakes, "Mathematical model for scheduling and staffing multiclinic health regions," European Journal of Operational Research, 41(3), 277-289 (1989).

Fries, B., "Bibliography of operations research in health-care systems," Operations Research, 24, 801-804 (1976).

Fuller, E., "Tackling scheduling problems using integer programming," Master Thesis, University of Wales Swansea, 1998.

Gillies, D. A., Nursing Management-A Systems Approach, Philadelphia, US America: W.B. Saunders, 1989.

Gray, J. J., D. McIntire, and H. J. Doller, "Preferences for specific work schedules: Foundation for an expert-system scheduling program," Computers in Nursing, 11(3), 115-121 (1993).

Howell, J. P., "Cyclical scheduling of nursing personnel," Hospitals, 40, 77-85 (1966).

Hung, R., "A cyclical schedule of 10-hour, four-day workweeks," Nursing Management, 22(5), 30-33 (1991).

Hung, R., "Improving productivity and quality through workforce scheduling," Industrial Management, 34(6), 4-6 (1992).

Hung, R., "Hospital Nurse scheduling," Journal of Nursing Administration, 25(7/8), 21-23 (1995).

Ikegami, A. and A. Niwa, "A subproblem-centric model and approach to the Nurse scheduling problem," Mathematical Programming, 97(3), 517-541 (2003).

Isken, M., "An implicit tour scheduling model with applications in healthcare," Annals of Operations Research, 128, 91-109 (2004).

Isken, M. W. and M. W. Hancock, "Tactical scheduling analysis for hospital ancillary units," Journal of the Society for Health Systems, 5(4), 11-24 (1998).

Isken, M. W. and W. Hancock, "A heuristic approach to Nurse scheduling in hospital units with non-stationary, urgent demand, and a fixed staff size," Journal of the Society for Health Systems, 2(2), 24-41 (1991).

Jan, A., M. Yamamoto, and A. Ohuchi, "Evolutionary algorithms for Nurse scheduling problem," in Proceedings of the 2000 Congress on Evolutionary Computation, CEC00, San Diego, ISBN 0-7803-6375-2, 2000, pp. 196-203.

Jaszkiewicz, A., "A metaheuristic approach to multiple objective nurse scheduling," Foundations of Computing and Decision Sciences, 22(3), 169-184 (1997).

Jaumard, B., F. Semet, and T. Vovor, “A generalized linear programming model for nurse scheduling," European Journal of Operational Research, 107, 1-18 (1998).

Jelinek, R. and J. Kavois, "Nurse staffing and scheduling: Past solutions and future directions," Journal of the Society for Health Systems, 3(4), 75-82 (1992). 
Kawanaka, H., K. Yamamoto, T. Yoshikawa, T. Shinogi, and S. Tsuruoka, "Genetic algorithm with the constraints for Nurse scheduling problem," in Proceedings of Congress on Evolutionary Computation, Seoul, IEEE Press, 2001, pp. 1123-1130.

Kostreva, M.M. and P. Genevier, "Nurses preferences vs. circadian rhythms in scheduling," Nurse Management, 20(7), 50-62 (1989).

Kostreva, M. and K. Jennings, "Nurse scheduling on a microcomputer," Computers and Operations Research, 18, 731-739 (1991).

Kumar, A. and R. Kapur, "Discrete simulation application-Scheduling staff for the emergency room," in E.A. MacNair, K.J. Musselman, and P. Heidelberger (eds.), Winter Simulation Conference Proceedings, IEEE, Washington, DC, 1989, pp. $1112-1120$

Lazaro, J. M. and P. Aristondo, "Using solver for Nurse scheduling," in Proceedings of Ilog Solver \& Ilog Schedule, First International Users' Conference (http://www.ilog.fr/products/solver/conference.html), Paris, 1995.

Li, H., A. Lim, and B. Rodrigues, "A hybrid AI approach for Nurse rostering problem," in Proceedings of the 2003 ACM Symposium on Applied Computing, ISBN 1-58113-624-2, 2003, pp. 730-735.

Liebman, J. S., J. P. Young, and M. Bellmore, "Allocation of Nursing personnel in an extended care facility," Health Services Research, 7, 209-220 (1972).

Lotfi, V. and R. Cerveny, "A final exam-scheduling package," Journal of the Operational Research Society, 42, 205-216 (1991).

Maier-Rothe, C. and H. B. Wolfe, “Cyclical scheduling and allocation of Nursing staff," Socio-Economic Planning Science, 7, 471-487 (1973)

Megeath, J. D., "Successful hospital personnel scheduling," Interfaces, 8(2), 55-60 (1978).

Meisels, A., E. Gudes, and G. Solotorevski, "Employee timetabling, constraint networks and knowledge-based rules: A mixed approach," in E. K. Burke and P. Ross (eds.), Practice and Theory of Automated Timetabling, First International Conference, Edinburgh, Springer, Lecture Notes in Computer Science, Vol. 1153, 1996, pp. 93-105.

Meisels, A., E. Gudes, and G. Solotorevski, "Combining rules and constraints for employee timetabling," Journal of Intelligent Systems, 12, 419-439 (1997).

Meisels, A. and N. Lusternik, "Experiments in networks of employee timetabling problems," in E. K. Burke and M. Carter (eds.), Practice and Theory of Automated Timetabling, Second International Conference, Toronto, Springer, Lecture Notes in Computer Science, vol. 1408, 1998, pp. 130-141.

Meisels, A. and A. Schaerf, "Modelling and solving employee timetabling problems," Annals of Mathematics and Artificial Intelligence, 39, 41-59 (2003).

Meyer auf'm Hofe, H., "ConPlan/SIEDAplan: Personnel assignment as a problem of hierarchical constraint satisfaction," in Proceedings of the Third International Conference on the Practical Application of Constraint Technology, London, 1997, pp. 257-271.

Meyer auf'm Hofe, H., "Solving rostering tasks as constraint optimization," in E. K. Burke and W. Erben (eds.), Practice and Theory of Automated Timetabling, Third International Conference, Konstanz, Springer, Lecture Notes in Computer Science, vol. 2079, 2001, pp. 191-212.

Millar, H. H. and M. Kiragu, "Cyclic and non-cylcic scheduling of $12 \mathrm{~h}$ shift nurses by network programming," European Journal of Operational Research, 104(3), 582-592 (1998).

Miller, M. L., "Implementing self-scheduling," The Journal of Nursing Administration, 14, 33-36 (March 1984).

Miller, H. E., W. Pierskalla, and G. Rath, "Nurse scheduling using mathematical programming," Operations Research, 24, 857-870 (1976).

Monk, T. H., "Advantages and disadvantages of rapidly rotating shift schedules. A circadian viewpoint," Human Factors, 28, 553-557 (1986).

Monk, T. H. and S. Folkard, Making Shift Work Tolerable, London, Taylor and Francis, ISBN $0850668220,1992$.

Morrow, K. L., "Using staffing and scheduling information to support change," Nursing Management, 25(5), 78-80 (1994).

Moz, M. and M. Pato, "Solving the problem of rerostering Nurse schedules with hard constraints: New multicommodity flow models," Annals of Operations Research, 128, 179-197 (2004).

Mueller, C. W. and J. C. McCloskey, "Nurses' job satisfaction: A proposed measure," Nursing Research, 39(2) 113-117 (1990).

Musa, A. and U. Saxena, "Scheduling Nurses using goal-programming techniques," IEE Transactions, 16, 216-221 (1984).

Muslija, N., J. Gaertner, and W. Slany, "Efficient generation of rotating workforce schedules," in E. K. Burke and W. Erben (eds.), Proceedings of the 3rd International Conference on the Practice and Theory of Automated Timetabling, ISBN 3-00-003866-3, 2000, pp. 314-332. 
Musliu, N., A. Schaerf, and W. Slany, "Local search for shift design, MIC'2001," in Proceedings of the 4th Metaheuristics International Conference, Porto, 2001, pp. 465-469.

Narasimhan, R., "An algorithm for single shift scheduling of hierarchical workforce," European Journal of Operational Research, 96, 113-121 (1996).

Nutt, P. C., "Decision-modeling methods used to design decision support systems for staffing," Medical Care, 22(11), 1002-1013 (1984).

Okada, M., "An approach to the generalised nurse scheduling problem-Generation of a deeclarative program to represent institution-specific knowledge," Computers and Biomedical Research, 25, 417-434 (1992).

Okada, M. and M. Okada, "Prolog-based system for Nursing staff scheduling implemented on a personal computer," Computers and Biomedical Research, 21, 53-63 (1988).

Oldenkamp, J. H., "Investigating reasoning in maternity care scheduling," Knowledge and Policy, 5(3), 67-76 (1992).

Ozkarahan, I., "A flexible Nurse scheduling support system," Computer Methods and Programs in Biomedicine, 30, 145-153 (1989).

Ozkarahan, I., "A disaggregation model of a flexible Nurse scheduling support system," Socio-Economical Planning Science, 25(1), 9-26 (1991).

Ozkarahan, I., "An integrated Nurse scheduling model," Journal of the Society for Health Systems, 3(2), 79-101 (1991).

Ozkarahan, I., "Allocation of surgical procedures to operating rooms," Journal of Medical Systems, 19(4), 333-352 (1995).

Ozkarahan, I., "Allocation of surgeries to operating rooms by goal programming," Journal of Medical Systems, 24(6), $339-378(2000)$

Ozkarahan, I. and J. E. Bailey, “Goal programming model subsystem of a flexible nurse scheduling support system,” IEEE Transactions, 16, 306-316 (1988).

Paechter, B., R. C. Rankin, A. Cumming, and T. C. Fogarty, Timetabling the classes of an Entire University with an Evolutionary Algorithm, Parallel Problem Solving from Nature (PPSN) V, Springer, LNCS 1498, 1998.

Petrovic, S., G. Beddoe, and G. Vanden Berghe, "Storing and adapting repair experiences in personnel rostering," in E. K. Burke and P. De Causmaecker (eds.), Practice and Theory of Automated Timetabling, Fourth International Conference, Gent, Springer, Lecture Notes in Computer Science, vol. 2740, 2003, pp. 185-186.

Prescott, P. A. and S. A. Bowen, "Controlling nursing turnover," Nursing Management, 18(6), 60-66 (1987).

Randhawa, S. U. and D. Sitompul, "A heuristic-based computerized Nurse scheduling system," Computers and Operations Research, 20(8), 837-844 (1993).

Ringl, K. K. and L. Dotson, "Self-scheduling for professional Nurses," Nursing Management, 20, 42-44 (1989).

Rosenbloom, E. S. and N. F. Goertzen, “Cyclic Nurse scheduling,” European Journal of Operational Research, 31, 19-23 (1987).

Scott, S., "Learning behaviour in a case-based workforce scheduler," in Proceedings of the 17th UK Planning and Scheduling Special Interest Group, 1998, pp. 217-219.

Scott, S. and R. M. Simpson, "Case-bases incorporating scheduling constraint dimensions: Experiences in Nurse rostering," in Smyth and Cunningham (eds.), Advances in Case-Based Reasoning, Springer, Lecture Notes in Artificial Intelligence, vol. 1488, 1998, pp. 392-401.

Scott, S., R. M. Simpson, and R. Ward, "Combining case-based reasoning and constraint logic programming techniques for packaged Nurse rostering systems," in Proceedings of the 3rd UK Case-Based Reasoning Workshop (1997).

Schaerf, A. and A. Meisels, "Solving employee timetabling problems by generalised local search," in Proceedings Italian $A I, 1999$, pp. 493-502.

Siferd, S. P. and W. C. Benton, "Workforce staffing and scheduling: Hospital nursing specific models," European Journal of Operational Research, 60, 233-246 (1992).

Silvestro, R. and C. Silvestro, "An evaluation of nurse rostering practices in the National Health Service," Journal of Advanced Nursing, 32(3), 525-535 (2000).

Sitompul, D. and S. Randhawa, "Nurse scheduling models: A state-of-the-art review," Journal of the Society of Health Systems, 2, 62-72 (1990).

Slowiński, R. and M. Hapke (eds.), Scheduling Under Fuzziness, Physica-Verlag, ISBN 3-7908-1249-8, 2000

Smith, L. D., "The application of an interactive algorithm to develop cyclical rotational schedules for Nursing personnel," INFOR, 14, 53-70 (February, 1976).

Smith, L. D., D. Bird, and A. Wiggins, "A computerised system to schedule nurses that recognises staff preferences," Hospital \& Health Service Administration, 19-35 (1979).

Smith, L. D., A. Wiggins, and D. Bird, "Post implementation experience with computer-assisted nurse scheduling in a large hospital," Information Systems and Operational Research, 17, 309-321 (1979). 
Smith, L. D. and A. Wiggins, "A computer-based Nurse scheduling system," Computers and Operations Research, 4(3), 195-212 (1977).

Smith-Daniels, V., S. Schweikhart, and D. Smith-Daniels, "Capacity management in health care services: Review and future research directions," Decision Sciences, 19, 891-919 (1988).

Tanomaru, J., "Staff scheduling by a genetic algorithm with heuristic operators," in Proceedings of the IEEE Conference on Evolutionary Computation, 456-461 (1995).

Tien, J. and A. Kamiyama, "On manpower scheduling algorithms," Society for Industrial and Applied Mathematics, 24(3), 275-287 (1982).

Trivedi, V. M. and M. Warner, "A branch and bound algorithm for optimum allocation of float nurses," Management Science, 22(9), 972-981 (1976).

Valouxis, C. and E. Housos, "Hybrid optimisation techniques for the workshift and rest assignment of nursing personnel," Artificial Intelligence in Medicine, 20, 155-175 (2000).

Warner, M., "Nurse staffing, scheduling, and reallocation in the hospital," Hospital \& Health Services Administration, 77-90 (1976).

Warner, M., "Scheduling Nursing personnel according to Nursing preference: A mathematical programming approach," Operations Research, 24, 842-856 (1976).

Warner, M., B. Keller, and S. Martel, "Automated Nurse scheduling," Journal of the Society for Health Systems, 2(2), 66-80.

Warner, M. and J. Prawda, "A mathematical programming model for scheduling Nursing personnel in a hospital," Management Science, 19, 411-422 (1972).

Weil, G., K. Heus, P. Francois, and M. Poujade, "Constraint programming for Nurse scheduling," in IEEE Engineering in Medicine and Biology, 1995, pp. 417-422.

Wiers, V. C. S., "A review of the applicability of OR and AI scheduling techniques in practice," OMEGA-the International Journal of Management Science, 25(2), 145-153 (1997).

Wilkinson, R. and S. Allison, "Alertness of night nurses: Two shift systems compared," Ergonomics, 32, 281-292 (1989).

Wolfe, H. and J. P. Young, "Staffing the Nursing unit: Part I," Nursing Res., 14(3), 236-234 (1965).

Wolfe, H., J. P. Young, and J. P., "Staffing the Nursing unit: Part II," Nursing Res., 14(4), 299-303 (1965).

Wren, A., "Scheduling, timetabling and rostering-A special relationship?" in E. K. Burke and P. Ross (eds.), Practice and Theory of Automated Timetabling, First International Conference, Edinburgh, Springer, Lecture Notes in Computer Science, vol. 1153, 1996, pp. 45-75. 